\title{
A computational study of the relative aromaticity of pyrrole, furan, thiophene and selenophene, and their Diels-Alder stereoselectivity
}

\author{
Veejendra K. Yadav* \\ Department of Chemistry, Indian Institute of Technology Kanpur, Kanpur 208016, India \\ vijendra@iitk.ac.in
}

\begin{abstract}
The collinearity of terminal $p$ orbitals of a diene with that of a dienophile is required for an effective overlap to result in $\sigma$ bond formation during the Diels-Alder reaction. The ease of the DA reaction of a cyclic diene with a given dienophile, therefore, must also depend on the distance between the termini of the diene. A distance larger than the unsaturated bond of the dienophile is expected to raise the energy of activation. This scenario has been amply demonstrated from the study of reactions of several dienes, some designed to serve the purpose, with different dienophiles. The five-ring heterocycles pyrrole, furan, thiophene and selenophene possess varying aromatic character for the varied resonance participation of the heteroatom lone pair with ring $\pi$ bonds. The aromaticity decreases in the same order due to: (a) the increasing $\sigma_{C-X}(X=$ heteroatom) bond length lifts the bond uniformity required for ring current, hence aromaticity, such as in benzene and (b) size-mismatch of the interacting lone pair orbital and the ring $p$ orbitals, especially in thiophene and selenophene, both allowing poor overlap in the ground state structures. It is demonstrated that increase alone in the activation energies of the DA reactions of pyrrole, furan, thiophene and selenophene cannot be considered a measure of relative aromaticity as often done and even theoretically attempted in many ways to prove just that. The separation of the termini of the diene has a much larger role in the determination of activation energy, especially in thiophene and selenophene, than their aromaticity profile. There cannot be a measure better than the relative intensity of heteroatom lone pair overlap with ring $\pi$ bonds, giving rise to a six-electron like system in following Hückel's $4 n+2$ rule, to assess the relative aromaticity.
\end{abstract}

Keywords: Relative aromaticity, Pyrrole, Furan, Thiophene, Selenophene, Diels-Alder reaction, Stereoselectivity 


\section{INTRODUCTION}

Aromaticity is an important concept in chemistry. ${ }^{1}$ It is not observable and also not a directly measurable quantity, many indices of aromaticity have therefore been introduced. Manogaran and Schaefer recently published an 'Aromaticity Index Based on Interaction Coordinates (AIBIC)' and observed that the relative aromaticity of the five-ring heterocycles followed the order thiophene > pyrrole $>$ furan. ${ }^{2}$ This order was previously also observed by the Nucleus-Independent Chemical Shift (NICS) studies carried out by Horner and Karadakov. ${ }^{3}$ The Topological Resonance Energy (TRE), ${ }_{4}^{4}$ Magnetic Resonance Energy (MRE) ${ }^{5}$ Ring Current (RC) and Ring Current Diamagnetic Susceptibility $\left(\chi_{c}\right)^{6}$ are among the other approaches used to determine the degree of aromaticity. Not all indices of aromaticity give consistent results among themselves and sometimes different aromaticity values derived from different indices lead to different aromaticity orders or different predictions. ${ }^{7}$ The suitability of the NICS and some other approaches for the prediction of aromaticity has been questioned. ${ }^{8}$ The aromaticity, in fact, is a challenge to theoretical and experimental chemists. ${ }^{9}$

The superior aromaticity of thiophene over pyrrole and furan appeared doubtful to us from the following arguments/observations:

(a) The aromaticity accrued to the ring is necessarily due to the conjugative interaction (Figure 1) of the heteroatom lone pair with the $\pi$ system of the ring to cause a sixelectron system, as in benzene, following Hückel's $4 n+2$ electrons rule for aromaticity. ${ }^{10}$

(b) The conjugative interaction must decrease in about the same order as the increase in the carbon-heteroatom $\sigma$ bond length. This is so because of the increased sizemismatch of the interacting $3 p$ orbital of $\mathrm{S}$ and $2 p$ orbitals of the ring $\pi$ system in thiophene. In selenophene, it is $4 p$ orbital of Se.

(c) The uniformity of bonds, ${ }^{11}$ which supports uniform distribution of electrons required for ring-current and magnetic susceptibility ${ }^{12}$ to enhance aromaticity, decreases dramatically in thiophene for the relatively long C-S and C-Se bonds in comparison to the $\mathrm{C}-\mathrm{C}$ bond.

(d) The relative rate of piperidinodenitration of 1-methyl-2,5-dinitropyrrole at $25{ }^{\circ} \mathrm{C}$ is markedly lower than those of 2,5-dinitrofuran and 2,5-dinitrothiophene, the $k_{\text {rel }}$ 
being 1.0, $2.4 \times 10^{6}$ and $4.4 \times 10^{3}$, respectively. ${ }^{13} \mathrm{~A}$ less significant difference is found with the rate of 1,4-dinitrobenzene $\left(k_{\text {rel }}=9.6\right)$. The rate-depressing effect may derive from the conjugative interaction of the ring heteroatom with the leaving $\mathrm{NO}_{2}$ group in the ground state. The low reactivity of pyrrole in nucleophilic substitution may, therefore, be mainly interpreted in terms of the stability of the ground state, since a significant conjugative interaction between the electronreleasing ring nitrogen and the nitro group, as occurring in the starting substrate, must be lost in the transition state (TS). Such an interaction is expected to be stronger than that of ring oxygen or sulfur for the stronger tendency of nitrogen to share its electrons, and may well be responsible for the position of the pyrrole system in the rate sequence. ${ }^{14}$

(e) The relative rates of bromination of pyrrole, furan, thiophene and benzene are $3 \times$ $10^{18}, 6 \times 10^{11}, 5 \times 10^{9}$ and 1.0 , respectively. ${ }^{15}$ Delocalization of lone pair into the ring decreases likewise.

(f) The study of reactivity of pyrrole, furan and thiophene in electrophilic substitution reactions suggests significant differences. The reactivity falls by approximately 10 orders of magnitude in the series pyrrole > furan > thiophene, and may be explained by the different conditions for delocalization of ring atom electron density, in the course of which overlap of $\pi$ orbitals of carbon atoms and lone pairs of the heteroatoms takes place. ${ }^{16}$ The delocalization of lone pair of nitrogen in pyrrole with ring $\pi$ system is clearly far greater than those of the oxygen in furan and sulfur in thiophene.

(g) The $\mathrm{pK}_{\mathrm{a}}$ of $\mathrm{C} 2-\mathrm{H}$ (Figure 2) in solvent tetrahydrofuran decreases in the order 39.5 $>35.6>33.0$ in pyrrole, furan and thiophene, respectively. ${ }^{17}$ The measured $\mathrm{pK}_{\mathrm{a}}$ values indicate higher electron density on $\mathrm{C} 2$ in pyrrole than in furan and thiophene. In other words, electron donation, through resonance, by $\mathrm{N}$ in pyrrole is larger than by $\mathrm{O}$ in furan and $\mathrm{S}$ in thiophene, in that order.

(h) The C3- and C4-Hs appear at ppm 6.20 in pyrrole, 6.25 in furan, and 6.92 in thiophene in ${ }^{1} \mathrm{H}$ NMR spectrum. ${ }^{18}$ These chemical shifts demonstrate decreasing resonance donor ability of the heteroatoms. One may be tempted to consider this as a consequence of increasing ring current and, thus, increasing deshielding and 
increasing aromaticity. The following discussions will make it clear that it is due to the relative resonance donor ability of the heteroatom and not the deshielding effect of increased ring current.

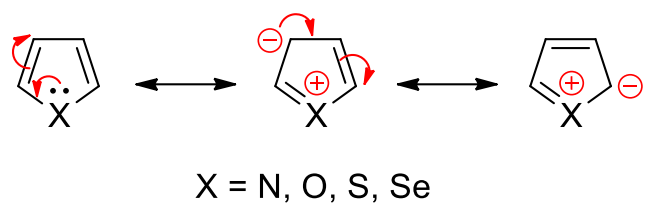

Figure 1. Conjugative interaction of heteroatom lone pair with ring $\pi$ system

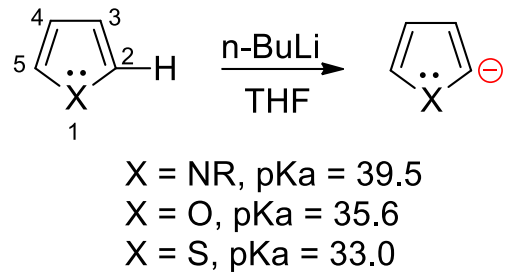

Figure 2. Relative $\mathrm{pK}_{\mathrm{a}}$ values of $\mathrm{C} 2$-hydrogen in five-ring heterocycles

The above observations point to the order pyrrole $>>$ furan $>$ thiophene for the overall ring electron density and, thus, the relative aromaticity which we wished to investigate herein. The intensely debated notion of superior aromaticity of thiophene over pyrrole and furan stemmed essentially from the failure of thiophene to react with maleic anhydride (MA) in Diels-Alder (DA) manner under the typical thermal alone conditions of the reaction, ${ }^{19}$ coupled with the solid understanding that more aromatic the system, larger was the activation barrier as it must overcome the aromatic stabilization. Thiophene, however, does react under high pressure conditions. ${ }^{20,21}$

Other than the resonance interaction of heteroatom lone pair with ring $\pi$ bonds to contribute to different reactivity features, including the facility of DA reaction, we proceeded with the very simple premise that as the distance $R$ between the termini of the cyclic diene increased with the increased $\sigma_{\mathrm{C}-\mathrm{X}}(\mathrm{X}=$ heteroatom $)$ bond length, the difficulty in attaining the collinear alignment of the terminal $p$ orbitals of the diene with those of the dienophile also increased, and so did the energy of activation. While aware that choosing dienes to test this theorem will be difficult because parameters other than $R$ must not change, we proceeded to design and investigate some systems. From here onward, we shall also include selenophene $(X=S e)$ in the discussion. Like thiophene 
$(\mathrm{X}=\mathrm{S})$, selenophene is also known to react in DA manner under high pressure. The product, however, extrudes selenium in situ to deliver a diene as shown in Scheme 1.22

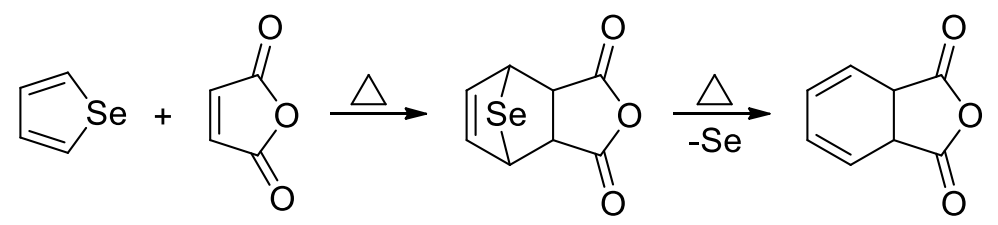

Scheme 1. DA reaction of selenophene with MA followed by Se extrusion

Computational Methods: The geometry optimizations of all the structures studied herein and the TS structure searches were carried out using the quantum chemical method MP2 at 6-31+G(d) and 6-311++G(d,p) levels using Gaussian $16 .{ }^{23}$ Optimized structures were verified as minima or first order saddle points on the potential energy surfaces by harmonic vibrational frequency analysis. The effects of solvents on the potential energy profiles of the DA reactions of pyrrole, furan, thiophene and selenophene with MA were estimated using the Conductor Polarized Continuum Model (CPCM) ${ }^{24}$ Orbital interactions were estimated by Natural Bond Orbital (NBO) analysis. ${ }^{25}$

\section{RESULTS AND DISCUSSION}

The interaction of the heteroatom lone pair (lp) with the $\pi$ system of the ring, $1 \mathrm{p} \rightarrow \pi^{*} \mathrm{C}=\mathrm{C}$, in the ground state was estimated to be $61.9 \mathrm{kcal} / \mathrm{mol}$ in pyrrole, $42.9 \mathrm{kcal} / \mathrm{mol}$ in furan, $41.9 \mathrm{kcal} / \mathrm{mol}$ in thiophene and $33.0 \mathrm{kcal} / \mathrm{mol}$ in selenophene. Since it is this very interaction that confers aromatic character to the ring by making up for the six-electron system, the aromaticity order requires to be pyrrole >> furan > thiophene > selenophene. The relative interaction intensities could be easily gleaned from the molecular orbitals shown in Figure 3.

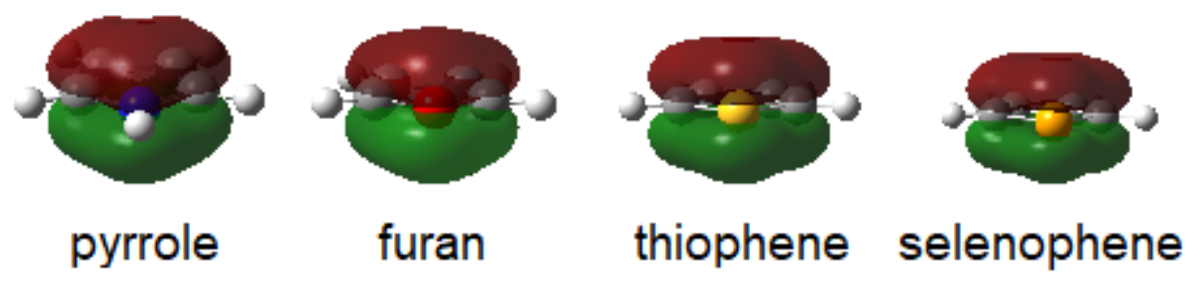

Figure 3. Molecular Orbitals showing interaction of heteroatom lone pair with ring $\pi$ bonds in pyrrole, furan, thiophene and selenophene at the same isovalue 
The interaction intensity decreases from pyrrole to selenophene, the difference between furan and thiophene is rather small.

The activation energy of DA reaction with a given dienophile is expected to rise with the rise in aromatic character of the ring system as the path to TS structure must negotiate with the resonance stabilization. Another important parameter that has largely been overlooked from the general description of relative aromaticity is the separation $R$ of the termini of diene in relation to the unsaturated bond in dienophile. ${ }^{26} R$ controls the efficacy of orbital overlap in TS structure for the emergent $\sigma_{\mathrm{CC}}$ bond formation. It is easy to agree that larger the $R$ from the unsaturated bond in dienophile, poorer shall be the collinearity of interaction, leading to higher energy of activation. The separation, enthalpy changes, and activation energies of the endo- and exo-DA reactions of pyrrole, furan, thiophene and selenophene with MA are collected in Table 1a.

Table 1a. $R$ and $\pi$ bond distances $(\AA)$ in the endo- and exo-TS structures for DA reactions of five-ring heterocycles with MA, activation energies $\left(\Delta G^{\ddagger}, \mathrm{kcal} / \mathrm{mol}\right)$ and enthalpy changes $(\Delta G, \mathrm{kcal} / \mathrm{mol})$ from gas phase calculations at MP2/6-311++G(d,p) level

\begin{tabular}{|l|c|c|c|c|c|c|c|c|}
\hline \multirow{2}{*}{ Diene } & \multicolumn{4}{|c|}{ endo-TS } & \multicolumn{4}{c|}{ exo-TS } \\
\cline { 2 - 9 } & $R$ & $\pi$ & $\Delta G^{\star}$ & $\Delta G$ & $\mathrm{R}$ & $\pi$ & $\Delta G^{\ddagger}$ & $\Delta G$ \\
\hline $\mathrm{X}=\mathrm{NH}$ & 2.1984 & 1.4250 & 22.7 & 7.3 & 2.1944 & 1.4300 & 21.1 & 5.6 \\
\hline $\mathrm{X}=\mathrm{O}$ & 2.1492 & 1.4123 & 18.5 & -0.0 & 2.1512 & 1.4117 & 19.1 & -1.7 \\
\hline $\mathrm{X}=\mathrm{S}$ & 2.3940 & 1.4148 & 24.6 & 0.9 & 2.3930 & 1.4149 & 26.0 & 0.3 \\
\hline $\mathrm{X}=\mathrm{Se}$ & 2.4836 & 1.4120 & 24.8 & -2.9 & 2.4805 & 1.4124 & 26.9 & -0.3 \\
\hline
\end{tabular}

$R$ rises from furan to pyrrole to thiophene to selenophene in both TS structures. The variation in $\pi$ bond length of MA is relatively very small except in the reaction with pyrrole, where it is the largest. The reason for the largest $\pi$ bond in reaction with pyrrole alone is probably due to pyrrole's reduced ability to deform in its migration to the TS structure and, hence, enhanced force on the dienophile to allow it negotiate with the diene for the reaction. The reduced ability of pyrrole to deform also translates into its highest aromaticity among the five-ring heterocycles. The activation free energy, $\Delta G^{\ddagger}$, is seen to rise with rise in $R$. The relatively reduced $R$ and also the $\pi$ bond in the 
$T S$ structure for the reaction of furan lower the activation energy in comparison to pyrrole. The reduced $R$ in furan in comparison to pyrrole is likely due to poorer resonance ability and larger electronegativity of oxygen over nitrogen. ${ }^{27}$

It is significant to note that $R$ always contracted in the TS structure from that in the ground state. The distances in the ground state structures are $2.1862 \AA$ in furan, $2.2538 \AA$ in pyrrole, $2.4673 \AA$ in thiophene and $2.5746 \AA$ in selenophene. The contraction in $R$ (by $0.0370 \AA$ in furan, $0.0554 \AA$ in pyrrole, $0.0733 \AA$ in thiophene and $0.0910 \AA$ in selenophene) in the TS structure is probably in the effort to ensure best possible collinearity of the interacting terminal orbitals.

The activation energy is not expected to rise linearly with $R$ because the facility to push the heteroatom out of the plane of the ring carbons in the TS structure must also rise as the overlap of the heteroatom lone pair with ring $\pi$ bonds weakens. This could be readily seen from the marginal difference in the activation energies of the reactions of thiophene and selenophene. By taking the activation energy alone, the aromaticity order from both the endo and exo modes of the reaction is selenophene $>$ thiophene $>$ pyrrole $>$ furan.

Table $1 \mathrm{~b} . R$ and $\mathrm{C} \equiv \mathrm{C}$ bond distances $(\AA)$ in the TS structures for DA reactions of five-ring heterocycles in reactions with acetylene-1,2-bisnitrile and acetylene, activation energies $\left(\Delta G^{\ddagger}, \mathrm{kcal} / \mathrm{mol}\right)$ and enthalpy changes $(\Delta G, \mathrm{kcal} / \mathrm{mol})$ from gas phase calculations at MP2/6-31+G(d) level

\begin{tabular}{|l|c|c|c|c|c|c|c|c|}
\hline \multirow{2}{*}{ Diene } & \multicolumn{4}{|c|}{$\mathrm{NCC} \equiv \mathrm{CCN}$} & \multicolumn{4}{c|}{$\mathrm{HC} \equiv \mathrm{CH}$} \\
\cline { 2 - 9 } & $R$ & $\equiv$ & $\Delta G^{\ddagger}$ & $\Delta G$ & $R$ & $\equiv$ & $\Delta G^{\ddagger}$ & $\Delta G$ \\
\hline $\mathrm{X}=\mathrm{NH}$ & 2.1937 & 1.2898 & 25.1 & 2.5 & 2.1959 & 1.2715 & 41.0 & 12.2 \\
\hline $\mathrm{X}=\mathrm{O}$ & 2.1528 & 1.2816 & 23.9 & -4.0 & 2.1530 & 1.2645 & 36.7 & 3.6 \\
\hline $\mathrm{X}=\mathrm{S}$ & 2.3876 & 1.2837 & 30.7 & -4.1 & 2.3924 & 1.2647 & 44.6 & 5.3 \\
\hline $\mathrm{X}=\mathrm{Se}$ & 2.4802 & 1.2803 & 23.1 & -17.7 & 2.4784 & 1.2621 & 40.1 & -4.9 \\
\hline
\end{tabular}

We have studied DA reactions of the five-ring heterocycles with weaker-than-MA dienophiles such acetylene-1,2-bisnitrile $(\mathrm{NCC} \equiv \mathrm{CCN})$ and acetylene $(\mathrm{HC} \equiv \mathrm{CH})$ with twin objective to avoid: (a) charge- and electron-transfer considerations ${ }^{28}$ and deal with the concerted process alone, and (b) the stereochemical endolexo issue. The charge- and electron-transfer mechanisms are more 
likely between significantly electron-rich and electron-deficient reactants. The results are collected in Table 1b. These results are at slight variance from those in Table 1a. From the activation energy, while the aromaticity order of the five-ring heterocycles is thiophene > pyrrole > furan > selenophene from reaction with acetylene-1,2-bisnitrileis, it is thiophene $>$ pyrrole $>$ selenophene $>$ furan from reaction with acetylene.

We describe below DA reactions of other cyclic dienes to demonstrate the effect of increased $R$ on the activation energy to support the $R$-hypothesis.

(1a) DA reactions of cyclopentadiene, silole and germole with MA: Cyclopentadiene, silole and germole are expected to behave like normal 1,3-dienes because there is no delocalization of the double bond character within the rings unlike pyrrole, furan, thiophene and selenophene. ${ }^{29}$ Rise in $R$ is therefore expected to raise the activation energy of the DA reaction.

Table 2a. $R$ and $\pi$ bond distances $(\AA)$ in the endo- and exo-TS structures for DA reactions of cyclopentadiene, silole and germole with MA, activation energies $\left(\Delta G^{\ddagger}, \mathrm{kcal} / \mathrm{mol}\right)$ and enthalpy changes $(\Delta G, \mathrm{kcal} / \mathrm{mol})$ in gas phase at MP2/6-311++G(d,p) level

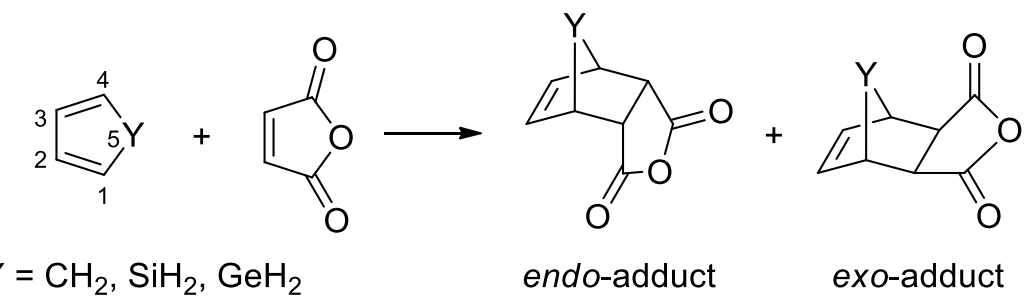

\begin{tabular}{|l|c|c|c|c|c|c|c|c|}
\hline \multirow{2}{*}{ Diene } & \multicolumn{4}{|c|}{ endo-TS } & \multicolumn{4}{c|}{ exo-TS } \\
\cline { 2 - 9 } & $R$ & $\pi$ & $\Delta G^{\ddagger}$ & $\Delta G$ & $R$ & $\pi$ & $\Delta G^{\ddagger}$ & $\Delta G$ \\
\hline $\mathrm{Y}=\mathrm{CH}_{2}$ & 2.3267 & 1.3870 & 9.8 & -20.4 & 2.3269 & 1.3890 & 12.3 & -20.4 \\
\hline $\mathrm{Y}=\mathrm{SiH}_{2}$ & 2.6370 & 1.3878 & 9.6 & -23.9 & 2.6356 & 1.3906 & 15.7 & -21.2 \\
\hline $\mathrm{Y}=\mathrm{GeH}_{2}$ & 2.6725 & 1.3898 & 10.5 & -24.7 & 2.6704 & 1.3913 & 16.4 & -21.1 \\
\hline
\end{tabular}

The relevant distances and activation energies are collected in Table 2a. Analysis of the numbers reveals that the activation energy has indeed increased with $R$. The increase in activation energy 
for exo addition is significantly larger than endo addition. This is likely due to the interplay of interactions such as maximum accumulation of unsaturation, ${ }^{30}$ secondary orbital interactions ${ }^{31}$ and dispersion forces ${ }^{32}$ in the endo-TS structure that are known to significantly influence the activation energy. It may also be that because of these additional interactions the activation energy of endo addition of silole is slightly lower than cyclopentadiene. However, the actual reason for the (small) discrepancy with silole only is not clear.

(1b) DA reactions of cyclopentadiene, silole and germole with acetylene-1,2-bisnitrile and acetylene: As with the five-ring heterocycles, we have also investigated the DA reactions of cyclopentadiene, silole and germole with acetylene-1,2-bisnitrile and acetylene to avoid the endolexo bifurcation and assess how the reaction profiles obeyed the $R$-hypothesis. The results are collected in Table 2b. The results with acetylenes are not the same as with MA. In particular, the activation energies of the reactions of silole and germole decreased, rather than increased, from that of cyclopentadiene. The clean $R$-compliant result from the exo addition of MA may, therefore, be fortuitous.

Table $2 \mathrm{~b} . R$ and $\mathrm{C} \equiv \mathrm{C}$ bond distances $(\AA)$ in the TS structures for DA reactions of cyclopentadiene, silole and germole with acetylene-1,2-bisnitrile and acetylene, activation energies $\left(\Delta G^{\ddagger}, \mathrm{kcal} / \mathrm{mol}\right)$ and enthalpy changes $(\Delta G, \mathrm{kcal} / \mathrm{mol})$ in gas phase at MP2/6-311++G(d,p) level

\begin{tabular}{|l|c|c|c|c|c|c|c|c|}
\hline \multirow{2}{*}{ Diene } & \multicolumn{4}{|c|}{$\mathrm{NCC} \equiv \mathrm{CCN}$} & \multicolumn{4}{c|}{$\mathrm{HC} \equiv \mathrm{CH}$} \\
\cline { 2 - 9 } & $R$ & $\equiv$ & $\Delta G^{\ddagger}$ & $\Delta G$ & $R$ & $\equiv$ & $\Delta G^{\ddagger}$ & $\Delta G$ \\
\hline $\mathrm{Y}=\mathrm{CH}_{2}$ & 2.3186 & 1.2661 & 14.0 & -29.1 & 2.3166 & 1.2514 & 25.5 & -19.6 \\
\hline $\mathrm{Y}=\mathrm{SiH}_{2}$ & 2.6327 & 1.2630 & 13.4 & -40.1 & 2.6269 & 1.2496 & 22.6 & -31.2 \\
\hline $\mathrm{Y}=\mathrm{GeH}_{2}$ & 2.6682 & 1.2648 & 13.9 & -41.8 & 2.6609 & 1.2510 & 23.6 & -32.7 \\
\hline
\end{tabular}

It is not that the $R$-hypothesis failed because the discrepancy can be explained. The $\sigma_{\mathrm{C} 5-\mathrm{H}}$ (hydrogen allylic to ring $\pi$ bond) in each instance is in hyperconjugative interaction with the ring $\pi$ bonds in the TS structure. ${ }^{33}$ In the reaction with acetylene-1,2-bisnitrile, the interactions $\sigma_{\mathrm{C}-\mathrm{H}}-\pi^{*}$ ring and $\pi_{\text {ring }}-\sigma^{*} \mathrm{C}-\mathrm{H}$ measure 17.9 and $10.4 \mathrm{kcal} / \mathrm{mol}$ in cyclopentadiene, 4.6 and $9.0 \mathrm{kcal} / \mathrm{mol}$ in silole, and 4.1 and $7.4 \mathrm{kcal} / \mathrm{mol}$ in germole. The combined effect of the two interactions in cyclopentadiene 
$(17.9-10.4=7.5 \mathrm{kcal} / \mathrm{mol})$ is that of net electron donation from $\sigma_{\mathrm{C} 5-\mathrm{H}}$ to the ring to impart aromatic character. In contrast, the rings are electron-depleted in silole and germole to render them somewhat anti-aromatic. Consequently, cyclopentadiene reacts with higher activation energy in comparison to silole and germole. This argument holds for the reactions with acetylene also as the interactions $\sigma_{\mathrm{C} 5-\mathrm{H}}-\pi^{*}$ ring and $\pi_{\text {ring }}-\sigma^{*}{ }_{\mathrm{C} 5-\mathrm{H}}$ measure, respectively, 15.0 and $5.5 \mathrm{kcal} / \mathrm{mol}$ in cyclopentadiene, 4.1 and $9.6 \mathrm{kcal} / \mathrm{mol}$ in silole, and 3.6 and $8.2 \mathrm{kcal} / \mathrm{mol}$ in germole.

The results of DA reactions of cyclopentadiene, silole, and germole with acetylene-1,2-bis nitrile and acetylene using the $6-31+\mathrm{G}(\mathrm{d})$ basis set are collected in Table 2c for a comparison with the results in Table $2 \mathrm{~b}$ using the $6-311++\mathrm{G}(\mathrm{d}, \mathrm{p})$ basis set. The $6-31+\mathrm{G}(\mathrm{d})$ results predict consistent fall in the activation energy from cyclopentadiene to germole. However, the sudden significant fall in activation energy of endo addition of acetylene-1,2-bisnitrile to germole is not understood. In the TS structures for the reactions of cyclopentadiene, silole and germole, the interactions $\sigma_{\mathrm{C} 5}$ $\mathrm{H}^{-} \pi^{*}{ }_{\text {ring }}$ and $\pi_{\text {ring }}-\sigma^{*}{ }_{\mathrm{C} 5-\mathrm{H}}$ measure, respectively, 16.9 and $8.9 \mathrm{kcal} / \mathrm{mol}, 4.7$ and $10.1 \mathrm{kcal} / \mathrm{mol}$, and 5.0 and $10.1 \mathrm{kcal} / \mathrm{mol}$ in reactions with acetylene-1,2-bisnitrile and 17.8 and $15.0 \mathrm{kcal} / \mathrm{mol}, 4.8$ and $15.5 \mathrm{kcal} / \mathrm{mol}$, and 5.4 and $15.2 \mathrm{kcal} / \mathrm{mol}$ in reactions with acetylene. This leads to the same scenario as discussed above as it too predicts fall in activation energy.

Table 2c. $R$ and $\mathrm{C} \equiv \mathrm{C}$ bond distances $(\AA)$ in the TS structures for DA reactions of cyclopentadiene, silole and germole with acetylene-1,2-bisnitrile and acetylene, activation energies $\left(\Delta G^{\ddagger}, \mathrm{kcal} / \mathrm{mol}\right)$ and enthalpy changes $(\Delta G, \mathrm{kcal} / \mathrm{mol})$ in gas phase at MP2/6-31+G(d) level

\begin{tabular}{|l|c|c|c|c|c|c|c|c|}
\hline \multirow{2}{*}{ Diene } & \multicolumn{4}{|c|}{$\mathrm{NCC} \equiv \mathrm{CCN}$} & \multicolumn{4}{c|}{$\mathrm{HC} \equiv \mathrm{CH}$} \\
\cline { 2 - 9 } & $R$ & $\equiv$ & $\Delta G^{\ddagger}$ & $\Delta G$ & $R$ & $\equiv$ & $\Delta G^{\ddagger}$ & $\Delta G$ \\
\hline $\mathrm{Y}=\mathrm{CH}_{2}$ & 2.3175 & 1.2685 & 15.3 & -29.1 & 2.3131 & 1.2540 & 28.4 & -18.2 \\
\hline $\mathrm{Y}=\mathrm{SiH}_{2}$ & 2.6353 & 1.2659 & 14.8 & -40.0 & 2.6253 & 1.2529 & 25.5 & -29.7 \\
\hline $\mathrm{Y}=\mathrm{GeH}_{2}$ & 2.6670 & 1.2647 & 8.0 & -49.5 & 2.6448 & 1.2537 & 22.6 & -34.2 \\
\hline
\end{tabular}

The switch over in the intensities of the $\sigma_{\mathrm{C} 5-\mathrm{H}}-\pi^{*}$ ring and $\pi_{\text {ring }}-\sigma^{*} \mathrm{C} 5-\mathrm{H}$ interactions from cyclopentadiene to silole and germole is interesting as it has implications on reaction kinetics. 
Also, in the activation energy falling regime under the obvious control of the combined $\sigma_{\mathrm{C} 5}$ $\mathrm{H}^{-}-\pi^{*}$ ring and $\pi_{\text {ring }}-\sigma^{*}{ }_{\mathrm{C} 5-\mathrm{H}}$ interactions, it is difficult to assign a role to $R$.

We notice from the above that the study of the effect of changing $R$ on the activation energies of DA reactions was complicated for the presence of other forces in the dienes. So, we continued with our search for more dienes to achieve the objective.

(2a) DA reactions of 1,3-cyclohexadiene and 1,3-cycloheptadiene with MA: These dienes were considered for the present investigation because the separation of the termini varied from 2.8429 $\AA$ in 1,3-cyclohexadiene to $3.1757 \AA$ in 1,3-cycloheptadiene in the ground state structures, and it was anticipated that they will follow the same order in the TS structures in reactions with dienophiles as well. The activation energy was, therefore, expected to rise from 1,3cyclohexadiene to 1,3-cycloheptadiene.

Table 3a. R and $\pi$ bond distances $(\AA)$ in the endo- and exo-TS structures for DA reactions of 1,3cyclohexadiene and 1,3-cycloheptadiene with MA, activation energies $\left(\Delta G^{\ddagger}, \mathrm{kcal} / \mathrm{mol}\right)$ and enthalpy changes $(\Delta G, \mathrm{kcal} / \mathrm{mol})$ in gas phase at MP2/6-31+G(d) level

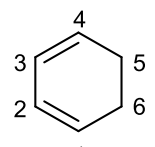

1

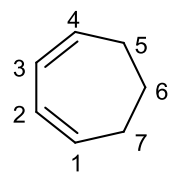

1,3-cycloheptadiene

1,3-cyclohexadiene

\begin{tabular}{|l|c|c|c|c|c|c|c|c|}
\hline \multirow{2}{*}{ Diene } & \multicolumn{4}{|c|}{ endo-TS } & \multicolumn{4}{c|}{ exo-TS } \\
\cline { 2 - 9 } & $R$ & $\pi$ & $\Delta G^{\ddagger}$ & $\Delta G$ & $R$ & $\pi$ & $\Delta G^{\ddagger}$ & $\Delta G$ \\
\hline $\mathrm{Y}=\left(\mathrm{CH}_{2}\right)_{2}$ & 2.7570 & 1.3846 & 16.0 & -29.2 & 2.7570 & 1.3894 & 20.2 & -27.2 \\
\hline $\mathrm{Y}=\left(\mathrm{CH}_{2}\right)_{3}$ & 3.0121 & 1.3906 & 20.1 & -31.0 & 3.0093 & 1.3970 & 27.3 & -27.3 \\
\hline
\end{tabular}

The relevant parameters for reactions with MA are collected in Table 3a. The activation energies, as expected, rose for both the endo and exo modes of the addition. The $R$-hypothesis holds. 
Scrutiny of orbital interactions in the endo-TS structures reveals $\sigma_{\mathrm{C}-\mathrm{H}}-\pi^{*}{ }_{\text {ring }}$ and $\pi_{\text {ring }}-\sigma^{*}{ }_{\mathrm{C}-\mathrm{H}}$ interactions to be 18.9 and $9.0 \mathrm{kcal} / \mathrm{mol}$ in 1,3-cyclohexadiene and 18.9 and $4.2 \mathrm{kcal} / \mathrm{mol}$ in 1,3 cycloheptadiene. The differential interaction $\left(\sigma_{\mathrm{C}-\mathrm{H}}-\pi^{*}{ }_{\text {ring }}\right)-\left(\pi_{\text {ring }}-\sigma^{*} \mathrm{C}-\mathrm{H}\right)$ rose from $9.9 \mathrm{kcal} / \mathrm{mol}$ in 1,3 -cyclohexadiene to $14.7 \mathrm{kcal} / \mathrm{mol}$ in 1,3 -cycloheptadiene. Likewise, the $\sigma_{\mathrm{C}-\mathrm{H}}-\pi^{*}$ ring and $\pi_{\text {ring }}-\sigma^{*} \mathrm{C}-\mathrm{H}$ interactions in the exo-TS structures are 20.3 and $8.4 \mathrm{kcal} / \mathrm{mol}$ in 1,3-cyclohexadiene and 21.2 and $5.4 \mathrm{kcal} / \mathrm{mol}$ in 1,3-cycloheptadiene. The difference here too has rose from 11.9 $\mathrm{kcal} / \mathrm{mol}$ in 1,3 -cyclohexadiene to $15.8 \mathrm{kcal} / \mathrm{mol}$ in 1,3 -cycloheptadiene.

The consequence of $\sigma_{\mathrm{C}-\mathrm{H}}-\pi^{*}$ ring $>\pi_{\text {ring }}-\sigma^{*} \mathrm{C}-\mathrm{H}$ is to raise the electron density of the diene and make it more reactive towards dienophiles to lower the activation energy. The activation energy is instead substantially raised from 1,3-cyclohexadiene to 1,3-cycloheptadiene due probably to a strong $R$-effect.

\section{(2b) DA reactions of 1,3-cyclohexadiene and 1,3-cycloheptadiene with acetylene-1,2-bisnitrile}

and acetylene: The reactions of 1,3-cyclohexadiene and 1,3-cycloheptadiene with acetylene-1,2bisnitrile and acetylene were studied next to bypass the endo/exo issue as before and assess the effect of increasing $R$. The results are collected in Table $3 \mathrm{~b}$. The activation energies have increased with $R$.

Table 3b. $R$ and $\mathrm{C} \equiv \mathrm{C}$ bond distances $(\AA)$ in the TS structures for DA reactions of cyclopentadiene, 1,3cyclohexadiene and 1,3-cycloheptadiene with acetylene-1,2-bisnitrile and acetylene, activation energies $\left(\Delta G^{\ddagger}, \mathrm{kcal} / \mathrm{mol}\right)$ and enthalpy changes $(\Delta G, \mathrm{kcal} / \mathrm{mol})$ in gas phase at MP2/6-31+G(d) level

\begin{tabular}{|l|c|c|c|c|c|c|c|c|}
\hline \multirow{2}{*}{ Diene } & \multicolumn{4}{|c|}{$\mathrm{NCC} \equiv \mathrm{CCN}$} & \multicolumn{4}{c|}{$\mathrm{HC} \equiv \mathrm{CH}$} \\
\cline { 2 - 9 } & $R$ & $\equiv$ & $\Delta G^{\ddagger}$ & $\Delta G$ & $R$ & $\equiv$ & $\Delta G^{\ddagger}$ & $\Delta G$ \\
\hline $\mathrm{Y}=\left(\mathrm{CH}_{2}\right)_{2}$ & 2.7591 & 1.2661 & 18.5 & -44.6 & 2.7374 & 1.2509 & 31.2 & -33.7 \\
\hline $\mathrm{Y}=\left(\mathrm{CH}_{2}\right)_{3}$ & 3.0114 & 1.2705 & 22.5 & -47.7 & 2.9851 & 1.2538 & 36.0 & -36.4 \\
\hline
\end{tabular}

The $\sigma_{\mathrm{C}-\mathrm{H}}-\pi^{*}$ ring and $\pi_{\text {ring }}-\sigma^{*} \mathrm{C}-\mathrm{H}$ interactions in the TS structures for reactions with acetylene-1,2bisnitrile are 19.7 and $8.7 \mathrm{kcal} / \mathrm{mol}$ in 1,3-cyclohexadiene and 20.3 and $4.1 \mathrm{kcal} / \mathrm{mol}$ in 1,3cycloheptadiene. The difference $\left(\sigma_{\mathrm{C}-\mathrm{H}}-\pi^{*}{ }_{\text {ring }}\right)-\left(\pi_{\text {ring }}-\sigma^{*} \mathrm{C}-\mathrm{H}\right)$ has increased from $11.0 \mathrm{kcal} / \mathrm{mol}$ in 1,3 -cyclohexadiene to $16.2 \mathrm{kcal} / \mathrm{mol}$ in 1,3 -cycloheptadiene. Likewise, the $\sigma_{\mathrm{C}-\mathrm{H}}-\pi^{*}$ ring and 
$\pi_{\text {ring }}-\sigma^{*} \mathrm{C}-\mathrm{H}$ interactions in the TS structures for reactions with acetylene are 16.7 and $9.4 \mathrm{kcal} / \mathrm{mol}$ in 1,3-cyclohexadiene and 18.1 and $5.6 \mathrm{kcal} / \mathrm{mol}$ in 1,3-cycloheptadiene. The difference of the two interactions here too has increased from $7.3 \mathrm{kcal} / \mathrm{mol}$ in 1,3 -cyclohexadiene to $12.5 \mathrm{kcal} / \mathrm{mol}$ in 1,3-cycloheptadiene. In spite of the net activation energy-lowering $\sigma_{\mathrm{C}-\mathrm{H}}-\pi{ }^{*}$ ring interaction raised, the increase in activation energy from 1,3-cyclohexadiene to 1,3-cycloheptadiene strongly favors the $R$-hypothesis. In other words, when we expect decrease in activation energy for favourable $\sigma_{\mathrm{C}}$ $\mathrm{H}-\pi^{*}$ ring interaction, we observe increase and this could solely be for the $R$-effect.

(3) DA reactions of 1,3-cyclohexadiene and 1,3-cyclooctadiene-6-yne with acetylene-1,2bisnitrile and acetylene: We have introduced an alkyne bond between C5 and C6 of 1,3cyclohexadiene to increase the separation of the termini of the diene by taking advantage of the linear alkyne geometry. Indeed, the distance between the termini is $2.8429 \AA$ in 1,3 cyclohexadiene and 3.6348 $\AA$ in 1,3-cyclooctadiene-6-yne. Accordingly, the activation energy was expected to rise in DA reactions with acetylene-1,2-bisnitrile and acetylene. The results are collected in Table 3c.

Table 3c. $R$ and $\mathrm{C} \equiv \mathrm{C}$ bond distances $(\AA)$ in the TS structures for DA reactions of 1,3-cyclohexadiene $(\mathrm{CHXDN})$ and 1,3-cycloctadiene-6-yne (COCTDNYN) with acetylene-1,2-bisnitrile and acetylene, activation energies $\left(\Delta G^{\ddagger}, \mathrm{kcal} / \mathrm{mol}\right)$ and enthalpy changes $(\Delta G, \mathrm{kcal} / \mathrm{mol})$ in gas phase at MP2/6-31+G(d) level

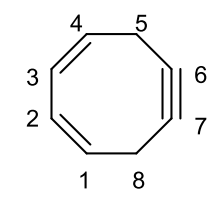

1,3-cyclooctadiene-6-yne

\begin{tabular}{|l|c|c|c|c|c|c|c|c|}
\hline \multirow{2}{*}{ Diene } & \multicolumn{4}{|c|}{$\mathrm{NCC} \equiv \mathrm{CCN}$} & \multicolumn{4}{c|}{$\mathrm{HC} \equiv \mathrm{CH}$} \\
\cline { 2 - 9 } & $R$ & $\equiv$ & $\Delta G^{*}$ & $\Delta G$ & $R$ & $\equiv$ & $\Delta G^{*}$ & $\Delta G$ \\
\hline CHXDN & 2.7591 & 1.2661 & 18.5 & -44.6 & 2.7374 & 1.2509 & 31.2 & -33.7 \\
\hline COCTDNYN & 3.3822 & 1.2734 & 22.4 & -59.7 & 3.3510 & 1.2546 & 35.3 & -50.1 \\
\hline
\end{tabular}

The $\sigma_{\mathrm{C}-\mathrm{H}}-\pi^{*}$ ring and $\pi_{\text {ring }}-\sigma^{*} \mathrm{C}-\mathrm{H}$ interactions in the TS structures for reactions with acetylene-1,2bisnitrile are 19.7 and $8.7 \mathrm{kcal} / \mathrm{mol}$ in 1,3-cyclohexadiene and 21.8 and $7.3 \mathrm{kcal} / \mathrm{mol}$ in 1,3- 
cyclooctadiene-6-yne. The difference $\left(\sigma_{\mathrm{C}-\mathrm{H}}-\pi^{*}{ }_{\text {ring }}\right)-\left(\pi_{\text {ring }}-\sigma^{*}{ }_{\mathrm{C}-\mathrm{H}}\right)$ has altered from $11.0 \mathrm{kcal} / \mathrm{mol}$ in 1,3-cyclohexadiene to $14.5 \mathrm{kcal} / \mathrm{mol}$ in 1,3-cyclooctadiene-6-yne. Likewise, the $\sigma_{\mathrm{C}-\mathrm{H}}-\pi^{*}$ ring and $\pi_{\text {ring }}-\sigma^{*}{ }_{\mathrm{C}-\mathrm{H}}$ interactions in the TS structures for reactions with acetylene are 16.7 and $9.4 \mathrm{kcal} / \mathrm{mol}$ in 1,3-cyclohexadiene and 19.4 and $8.8 \mathrm{kcal} / \mathrm{mol}$ in 1,3-cycloheptadiene. The difference here too has altered from $7.3 \mathrm{kcal} / \mathrm{mol}$ in 1,3-cyclohexadiene to $10.6 \mathrm{kcal} / \mathrm{mol}$ in 1,3-cyclooctadiene-6-yne. In spite of the increased net activation energy-lowering $\sigma_{\mathrm{C}-\mathrm{H}}-\pi^{*}$ ring interaction, the raise in the activation energy of 1,3-cyclooctadiene-6-yne could be due only to the $R$-effect.

Table 3d. Activation free energies $\left(\Delta G^{\ddagger}, \mathrm{kcal} / \mathrm{mol}\right)$, enthalpy changes $(\Delta G, \mathrm{kcal} / \mathrm{mol}), \sigma_{\mathrm{C}-\mathrm{X}}-\pi^{*}$ ring and $\pi_{\text {ring }}-\sigma^{*} \mathrm{C}-\mathrm{X}$ interactions $(\mathrm{kcal} / \mathrm{mol})$ in the endo-TS structures for DA reactions of butadiene, 1-Mebutadiene, 1,4-bis-Me-butadiene, 1- $\mathrm{CF}_{3}$-butadiene, and 1,4-bis- $\mathrm{CF}_{3}$-butadiene with $\mathrm{MA}$ in gas phase at MP2/6-31+G(d) level

$$
\begin{aligned}
& X \sqrt{1} L_{Y} \\
& \mathrm{X}=\mathrm{Y}=\mathrm{H} \text {, butadiene } \\
& \mathrm{X}=\mathrm{H}, \mathrm{Y}=\mathrm{Me} \text {, 1-Me-butadiene } \\
& X=Y=M e, 1,4 \text {-bis-Me-butadiene } \\
& \mathrm{X}=\mathrm{H}, \mathrm{Y}=\mathrm{CF}_{3} \text {, 1-CF3-butadiene } \\
& \mathrm{X}=\mathrm{Y}=\mathrm{CF}_{3}, 1,4 \text {-bis- } \mathrm{CF}_{3} \text {-butadiene }
\end{aligned}
$$

\begin{tabular}{|l|c|c|c|c|}
\hline \multirow{2}{*}{ Diene } & \multicolumn{4}{|c|}{ endo-TS } \\
\cline { 2 - 5 } & $\Delta G$ & $\Delta G^{\ddagger}$ & $\sigma_{\mathrm{C}-\mathrm{X}}-\pi^{*}$ ring & $\pi_{\text {ring }}-\sigma^{*} \mathrm{C}-\mathrm{X}$ \\
\hline butadiene & -33.3 & 16.6 & - & - \\
\hline 1-Me-butadiene & -31.2 & 14.5 & 9.8 & 4.6 \\
\hline 1,4-bis-Me-butadiene & -28.9 & 12.4 & 18.8 & 9.2 \\
\hline 1-CF - -butadiene & -28.4 & 19.5 & 1.8 & 12.5 \\
\hline 1,4-bis-CF - -butadiene & -23.7 & 22.3 & 3.8 & 22.5 \\
\hline
\end{tabular}

That indeed the allylic hydrogen lowers the activation energies of DA reactions of dienes such as 1,3-cyclohexadiene, 1,3-cycloheptadiene and 1,3-cyclooctadiene-6-yne through $\sigma_{\mathrm{C}-\mathrm{H}}-\pi^{*}$ ring interaction requires to be amply shown. An electron-attracting substituent, on the contrary, is expected to raise the activation energy through $\pi_{\text {ring }}-\sigma^{*} \mathrm{C}-\mathrm{X}(\mathrm{X}=$ allylic substituent $)$ interaction. 
Unlike the five-ring dienes, these dienes do not acquire aromatic or anti-aromatic character where the effect of the net interaction will be quite the reverse. We have studied the DA reactions of butadiene, 1-methylbutadiene, 1,4-bis-Me-butadiene, 1- $\mathrm{CF}_{3}$-butadiene and 1,4-bis- $\mathrm{CF}_{3}$-butadiene with MA. The data is collected in Table $3 \mathrm{~d}$.

The activation energy decreases from $16.6 \mathrm{kcal} / \mathrm{mol}$ for butadiene to $14.5 \mathrm{kcal} / \mathrm{mol}$ for 1 -Mebutadiene and $12.4 \mathrm{kcal} / \mathrm{mol}$ for 1,4-bis-Me-butadiene as the difference of the electron-enhancing interaction $\sigma_{\mathrm{C}-\mathrm{H}}-\pi^{*}$ ring exceeds the electron-depleting interaction $\pi_{\text {ring }}-\sigma^{*} \mathrm{C}-\mathrm{X} / \mathrm{Y}$ by 5.2 and 9.6 $\mathrm{kcal} / \mathrm{mol}$, respectively. Contra to this, the activation energy rises from $16.6 \mathrm{kcal} / \mathrm{mol}$ for butadiene to $19.5 \mathrm{kcal} / \mathrm{mol}$ for $1-\mathrm{CF}_{3}$-butadiene and $22.3 \mathrm{kcal} / \mathrm{mol}$ for $1,4-\mathrm{bis}-\mathrm{CF}_{3}$-butadiene as the electrondepleting interaction $\pi_{\text {ring }}-\sigma^{*} \mathrm{C}-\mathrm{X} / \mathrm{Y}$ exceeds the electron-enhancing interaction $\sigma_{\mathrm{C}-\mathrm{H}}-\pi{ }^{*}$ ring by 10.7 and $18.7 \mathrm{kcal} / \mathrm{mol}$, respectively.

The above discussions substantially supports the $R$-hypothesis, i.e., an increased $R$ increases the activation energy of the DA reaction of a diene with a given dienophile. The $R$-hypothesis was floated long ago, ${ }^{26}$ but never used in connection with the relative aromaticity of five-ring heterocycles as it is done in here. The $R$-effect and overlap intensity of the heteroatom lone pair with the ring $\pi$ bonds together determine the activation energy of the DA reaction and the aromaticity order is pyrrole $>$ furan $>$ thiophene $>$ selenophene.

(4) DA reactions of 6-oxa-1,3-cycloheptadiene, 6-aza-1,3-cycloheptadiene, 6-thia-1,3cycloheptadiene and 6-selena-1,3-cycloheptadiene with MA: The idea behind studying these molecules was that the changing $\sigma_{\mathrm{C}-\mathrm{X}}$ bond length will also change $R$ as in the five-ring heterocycles. Indeed, $R$ in the ground state structure changed from $3.1098 \AA$ in 6-oxa-1,3cycloheptadiene to $3.1422 \AA$ in 6-aza-1,3-cycloheptadiene to $3.2312 \AA$ in 6-selena-1,3cycloheptadiene to 3.2351 $\AA$ in 6-thia-1,3-cycloheptadiene. The $R$ changed, respectively, to 2.9673 $\AA, 2.9868 \AA, 3.0933 \AA$ and $3.0554 \AA$ in the endo-TSs for DA reaction with MA. It must be noted that the distance in the Se-analog is larger than S-analog by $0.0379 \AA$ in the TS. The distance and energy parameters are collected in Table 4.

The net of interactions $\sigma_{\mathrm{C}-\mathrm{H}-} \pi^{*}$ ring and $\pi_{\text {ring }}-\sigma^{*} \mathrm{CH}$ in the TS structures measures $10.2 \mathrm{kcal} / \mathrm{mol}, 11.9$ $\mathrm{kcal} / \mathrm{mol}, 12.9 \mathrm{kcal} / \mathrm{mol}$, and $12.6 \mathrm{kcal} / \mathrm{mol}$ in the reactions of 6-oxa-, 6-aza-, 6-thia- and 6-selena- 
1,3-cycloheptadienes, respectively. This interaction raises the reactivity of the respective diene. Must this interaction be the sole control of the reaction, the reactivity order will be 6-thia- > 6selena- > 6-aza- > 6-oxa-1,3-cycloheptadiene. Likewise, if $R$ alone were the control factor, the reactivity order will be 6-oxa- > 6-aza- > 6-thia- > 6-selena-1,3-cycloheptadiene. However, the reactivity order from the activation energies is 6-aza- > 6-oxa- > 6-selena- > 6-thia-1,3cycloheptadiene. $R$ and the net of the interactions $\sigma_{\mathrm{C}-\mathrm{H}-} \pi^{*}$ ring and $\pi_{\text {ring }}-\sigma^{*} \mathrm{CH}$ appear to collectively control the reaction.

Table 4. $R$ and $\pi$ bond distances $(\AA)$ in the endo-TS structures for DA reactions of 6-oxa-1,3cycloheptadiene, 6-aza-1,3-cycloheptadiene, 6-thia-1,3-cycloheptadiene and 6-selena-1,3-cycloheptadiene with MA, activation energies $\left(\Delta G^{\ddagger}, \mathrm{kcal} / \mathrm{mol}\right)$ and enthalpy changes $(\Delta G, \mathrm{kcal} / \mathrm{mol})$ from gas phase calculations at MP2/6-31+G(d) level

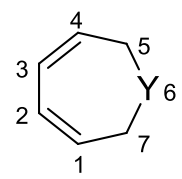

$Y=0,6$-oxa-,13-cycloheptadiene

$\mathrm{Y}=\mathrm{NH}, 6$-aza-1,3-cycloheptadiene

$\mathrm{Y}=\mathrm{S}, 6$-thia-1,3-cycloheptadiene

$\mathrm{Y}=\mathrm{Se}, 6$-selena-1,3-cycloheptadiene

\begin{tabular}{|c|c|c|c|c|}
\hline \multirow{2}{*}{ Diene } & \multicolumn{4}{|c|}{ endo-TS } \\
\cline { 2 - 5 } & $R$ & $\pi$ & $\Delta G^{\ddagger}$ & $\Delta G$ \\
\hline $\mathrm{Y}=\mathrm{O}$ & 2.9673 & 1.3878 & 17.1 & -33.6 \\
\hline $\mathrm{Y}=\mathrm{NH}$ & 2.9868 & 1.3864 & 16.1 & -35.4 \\
\hline $\mathrm{Y}=\mathrm{S}$ & 3.0554 & 1.3892 & 20.4 & -33.1 \\
\hline $\mathrm{Y}=\mathrm{Se}$ & 3.0933 & 1.3893 & 18.1 & -36.3 \\
\hline
\end{tabular}

(5) DA reactions of 2,3-cyclopropano-6-oxa-1,3-cycloheptadiene, 2,3-cyclobutano-6-oxa-1,3cycloheptadiene and 2,3-cyclopentano-6-oxa-1,3-cycloheptadiene with MA: These molecules were designed to take advantage of the different geometrical constraints of three-, four- and fivemembered rings to manipulate $R$, which was expected to decrease in that order. Indeed, $R$ varied from $3.3516 \AA$ to $3.2652 \AA$ to $3.1376 \AA$ in the ground state structures of 2,3-cyclopropano-, 2,3 cyclobutano- and 2,3-cyclopentano-6-oxa-1,3-cycloheptadienes, respectively. As above, $R$ was 
expected to maintain a similar decreasing order in the TS structures for DA reaction with MA. The relevant structural and energy parameters are collected in Table 5.

Table 5. Enthalpy changes $(\Delta G, \mathrm{kcal} / \mathrm{mol})$, activation free energies $\left(\Delta G^{\ddagger}, \mathrm{kcal} / \mathrm{mol}\right), \sigma_{\mathrm{C}-\mathrm{H}}-\pi^{*}{ }_{\mathrm{ring}}$ and $\pi_{\text {ring }}-\sigma^{*}{ }_{\mathrm{C}-\mathrm{H}}$ interactions $(\mathrm{kcal} / \mathrm{mol})$ in the endo-TS structures for DA reactions of 2,3-cyclopropano-6-oxa1,3-cycloheptadiene, 2,3-cyclobutano-6-oxa-1,3-cycloheptadiene and 2,3-cyclopentano-6-oxa-1,3cycloheptadiene with MA in gas phase at MP2/6-31+G(d) level

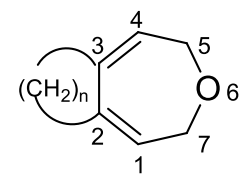

$\mathrm{n}=1 ; 2,3$-cyclopropano-6-oxa-1,3-cycloheptadiene

$\mathrm{n}=2 ; 2,3$-cyclobutano-6-oxa-1,3-cycloheptadiene

$\mathrm{n}=3$; 2,3-cyclopentano-6-oxa-1,3-cycloheptadiene

\begin{tabular}{|c|c|c|c|c|c|}
\hline \multirow{2}{*}{ Diene } & \multicolumn{5}{|c|}{ endo-TS } \\
\cline { 2 - 6 } & $R$ & $\Delta G$ & $\Delta G^{\ddagger}$ & $\sigma_{\mathrm{C}-\mathrm{H}}-\pi^{*}$ ring & $\pi_{\text {ring }}-\sigma^{*}{ }_{\mathrm{C}-\mathrm{H}}$ \\
\hline $\mathrm{n}=1$ & 3.1107 & -33.3 & 16.6 & 8.6 & 3.9 \\
\hline $\mathrm{n}=2$ & 3.0587 & -28.0 & 13.8 & 12.3 & 4.6 \\
\hline $\mathrm{n}=3$ & 2.9895 & -35.8 & 11.8 & 14.1 & 5.6 \\
\hline
\end{tabular}

The activation energy decreased with $R$. The net of the interactions $\sigma_{\mathrm{C}-\mathrm{H}}-\pi^{*}$ ring and $\pi_{\text {ring }}-\sigma^{*} \mathrm{C}-\mathrm{H}$ increased from $4.7 \mathrm{kcal} / \mathrm{mol}$ in cyclopropano-derivative to $7.7 \mathrm{kcal} / \mathrm{mol}$ in cyclobutano-derivative to $8.5 \mathrm{kcal} / \mathrm{mol}$ in cyclopentano-derivative. The increasing interaction will lower the energy of activation. So, we can safely assume that the fall in activation energy is due to a combined effect of decreasing $R$ and the increasing diene-activating $\sigma_{\mathrm{C}-\mathrm{H}}-\pi^{*}$ ring interaction.

Having established the role of $R$ and the diene-activating or deactivating orbital interactions, we aimed to study clearly aromatic substrates wherein $R$ varied little but there were known differences in the aromaticity to see changes in activation energies of DA reactions. We chose (a) benzene, pyridine and 1,4-diazine, (b) naphthalene, 1-azanaphthalene and 1,4-diazanaphthalene, (c) anthracene, 9-azaanthracene and 9,10-diazaanthracene, and (d) benzene, naphthalene and 
anthracene, and located the TS structures for reactions with dienophiles. The results are described hereunder.

(6) DA reactions of benzene, pyridine and 1,4-diazine with acetylene-1,2-bisnitrile and acetylene: The uniformity of ring bonds is one major requirement for ring current and, hence, aromaticity. Any disruption in bond-uniformity reduces the aromaticity and such is the case with pyridine and 1,4-diazine. Pyridine is known to possess slightly lower resonance energy than benzene. ${ }^{34}$ An extension of this argument would make 1,4-diazine possess lower resonance energy than pyridine. For the reactions of pyridine and 1,4-diazine, we chose 1,4-positions for the DA reaction $^{35}$ as the nitrogen centre is the source of said non-uniformity of bonds. The relevant structural and energy parameters are collected in Table 6. Surprisingly, the activation energy is seen to have increased in the order the resonance energy decreased. It is equally surprising to note the activation energy decrease for reaction across 2,4-positions of pyridine and 1,4-diazine (see footnotes to Table 6). The noted positional dependence of activation energy may be a good tool to test bond-uniformity.

Table 6. $R$ and $\mathrm{C} \equiv \mathrm{C}$ bond distances $(\AA)$ in the TS structures for DA reactions of benzene, pyridine and 1,4diazine with acetylene-1,2-bisnitrile and acetylene, activation energies $\left(\Delta G^{\ddagger}, \mathrm{kcal} / \mathrm{mol}\right)$ and enthalpy changes $(\Delta G, \mathrm{kcal} / \mathrm{mol})$ in gas phase at MP2/6-31+G(d) level

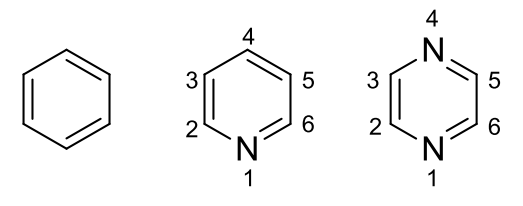

benzene pyridine 1,4-diazine

\begin{tabular}{|l|c|c|c|c|c|c|c|c|}
\hline \multirow{2}{*}{ Diene } & \multicolumn{4}{|c|}{$\mathrm{NCC} \equiv \mathrm{CCN}$} & \multicolumn{4}{c|}{$\mathrm{HC} \equiv \mathrm{CH}$} \\
\cline { 2 - 9 } & $R$ & $\equiv$ & $\Delta G^{\ddagger}$ & $\Delta G$ & $R$ & $\equiv$ & $\Delta G^{\ddagger}$ & $\Delta G$ \\
\hline benzene & 2.6587 & 1.2848 & 35.7 & 1.6 & 2.6547 & 1.2655 & 48.5 & 12.0 \\
\hline pyridine $^{\mathrm{a}}$ & 2.6529 & 1.2895 & 49.2 & 19.5 & 2.6529 & 1.2674 & 57.7 & 24.2 \\
\hline $1,4-$ diazine $^{\mathrm{b}}$ & 2.6477 & 1.2912 & 64.3 & 37.4 & 2.6511 & 1.2716 & 69.0 & 41.6 \\
\hline
\end{tabular}

${ }^{\mathrm{a}} \Delta G^{\ddagger}=32.8 \mathrm{kcal} / \mathrm{mol}$ for DA reaction across positions 2 and 4 with $\mathrm{NCC} \equiv \mathrm{CCN}$.

${ }^{\mathrm{b}} \Delta G^{\ddagger}=29.6 \mathrm{kcal} / \mathrm{mol}$ for DA reaction across positions 2 and 4 with $\mathrm{NCC} \equiv \mathrm{CCN}$. 
(7) DA reactions of naphthalene, 1-azanaphthalene and 1,4-diazanaphthalene with cyclopropene: Naphthalene, 1-azanaphthalene and 1,4-diazanaphthalene are the benzoderivatives of benzene, pyridine and 1,4-diazine, respectively, and, hence, they will have decreasing resonance energy. We have studied DA reactions of these aromatics with cyclopropene. The reaction was kept exo to the benzene ring in each instance as shown in Scheme $2 .{ }^{36}$ The relevant structural and energy parameters are collected in Table 7.

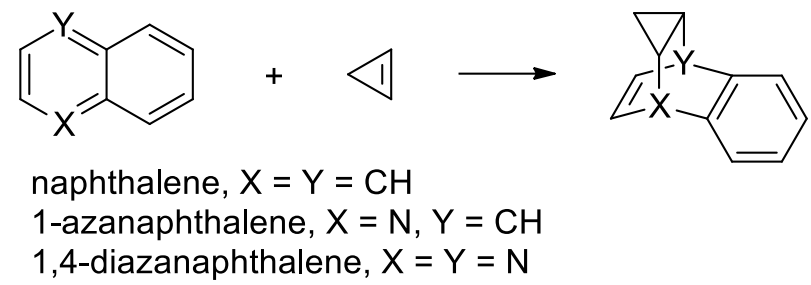

Scheme 2. DA reactions of naphthalene, 1-azanaphthalene and 1,4-diazanaphthalene

Table 7. $R$ and $\pi$ bond distances $(\AA)$ in the TS structures for DA reactions of naphthalene, 1-azanaphthalene and 1,4-diazanaphthalene with cyclopropene, activation energies $\left(\Delta G^{\star}, \mathrm{kcal} / \mathrm{mol}\right)$ and enthalpy changes $(\Delta G, \mathrm{kcal} / \mathrm{mol})$ in gas phase at MP2/6-31+G(d) level

\begin{tabular}{|c|c|c|c|c|}
\hline \multirow{2}{*}{ Diene } & \multicolumn{4}{|c|}{ cyclopropene } \\
\cline { 2 - 5 } & $R$ & $\pi$ & $\Delta G^{\ddagger}$ & $\Delta G$ \\
\hline naphthalene & 2.7315 & 1.3562 & 23.0 & -19.3 \\
\hline 1-azanaphthalene & 2.7370 & 1.3663 & 28.5 & -5.0 \\
\hline 1,4-diazanaphthalene & 2.7339 & 1.3787 & 37.5 & 10.4 \\
\hline
\end{tabular}

Here also, the activation energy is seen to have risen from naphthalene to 1-azanaphthalene to 1,4 diazanaphthalene concurrent with decline in the resonance energy.

(8) DA reactions of anthracene, 9-azaanthracene and 9,10-diazaanthracene with cyclopropene: The DA reactions of anthracene, 9-azaanthracene and 9,10-diazaanthracene with cyclopropene were studied next for further confirmation of the above results. Anthracene has 24 $\mathrm{kcal} / \mathrm{mol}$ less resonance energy than $3 \times$ benzene rings. The 9-azaanthracene and 9,10diazaanthracene will have further less resonance energy than anthracene for the same reason as for 
benzene and pyridine. The relevant structural and energy parameters are collected in Table 8 . The activation energy again rose significantly as the resonance energy of the system decreased.

Table 8. $R$ and $\pi$ bond distances $(\AA)$ in the TS structures for DA reactions of naphthalene, 1-azanaphthalene and 1,4-diazanaphthalene with cyclopropene, activation energies $\left(\Delta G^{\ddagger}, \mathrm{kcal} / \mathrm{mol}\right)$ and enthalpy changes $(\Delta G, \mathrm{kcal} / \mathrm{mol})$ in gas phase at $\mathrm{MP} 2 / 6-31+\mathrm{G}(\mathrm{d})$ level<smiles>c1ccc2cc3ccccc3cc2c1</smiles>

anthracene<smiles>c1ccc2nc3ccccc3cc2c1</smiles>

9-azaanthracene

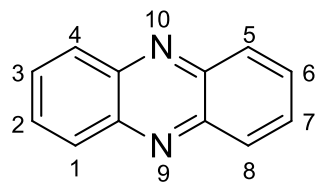

9,10-diazaanthracene

\begin{tabular}{|c|c|c|c|c|}
\hline \multirow{2}{*}{ Diene } & \multicolumn{4}{|c|}{ cyclopropene } \\
\cline { 2 - 5 } & $R$ & $\pi$ & $\Delta G^{\ddagger}$ & $\Delta G$ \\
\hline anthracene & 2.7595 & 1.3443 & 11.9 & -43.2 \\
\hline 1-azaanthracene & 2.7680 & 1.3550 & 19.1 & -25.5 \\
\hline 9,10-diazaanthracene & 2.8712 & 1.3674 & 27.0 & -9.2 \\
\hline
\end{tabular}

(9) DA reactions of benzene, naphthalene, and anthracene with acetylene-1,2-bisnitrile: The all carbon systems benzene, naphthalene and anthracene were studied for DA reaction with acetylene-1,2-bisnitrile. Anthracene has $24 \mathrm{kcal} / \mathrm{mol}$ less resonance energy than $3 \times$ benzene rings. Likewise, naphthalene has $11 \mathrm{kcal} / \mathrm{mol}$ less resonance energy than $2 \times$ benzene rings. The drop in resonance energy must result in drop in activation energy. The data is collected in Table 9.

Table 9. $R$ and $\equiv$ bond distances $(\AA)$ in TS structures for DA reactions of benzene, naphthalene and anthracene with acetylene-1,2-bisnitrile, activation energies $\left(\Delta G^{\ddagger}, \mathrm{kcal} / \mathrm{mol}\right)$ and enthalpy changes $(\Delta G$, $\mathrm{kcal} / \mathrm{mol})$ in gas phase at MP2/6-31+G(d) level

\begin{tabular}{|l|c|c|c|c|}
\hline \multirow{2}{*}{ Diene } & \multicolumn{4}{|c|}{$\mathrm{NCC} \equiv \mathrm{CCN}$} \\
\cline { 2 - 5 } & $R$ & $\equiv$ & $\Delta G^{*}$ & $\Delta G$ \\
\hline benzene & 2.6587 & 1.2848 & 35.7 & 1.6 \\
\hline naphthalene & 2.6858 & 1.2812 & 26.4 & -13.8 \\
\hline anthracene & 2.7124 & 1.2752 & 12.3 & -37.4 \\
\hline
\end{tabular}


The activation energy is now indeed seen to decrease with the resonance energy from $35.7 \mathrm{kcal} / \mathrm{mol}$ for benzene to $26.4 \mathrm{kcal} / \mathrm{mol}$ for naphthalene and $12.3 \mathrm{kcal} / \mathrm{mol}$ for anthracene. The drop in the activation energy is significantly large, almost as large as the drop in the resonance energy. Indeed, more the resonance energy, more energy is required to deform it for a DA reaction.

We have verified the relationship of resonance and deformation energies by studying the reactions given in Table 9. The difference of the free energies of a reactant in the ground and TS structures constitutes deformation free energy $\left(\Delta D^{\ddagger}\right)$. We treat the difference of the sum of deformation free energies of the reactants and the actual TS structure free energy as stabilization free energy $\left(\Delta S^{\sharp}\right)$ arising from orbital and other interactions. The deformation free energy of each reactant and also the stabilization free energy of the reaction in each instance is collected in Table 10.

Table 10. Deformation free energies $\left(\Delta D^{\ddagger}, \mathrm{kcal} / \mathrm{mol}\right)$ and stabilization free energies $\left(\Delta S^{\ddagger}, \mathrm{kcal} / \mathrm{mol}\right)$ for the DA reactions of benzene, naphthalene and anthracene with acetylene-1,2-bisnitrile (ABN) in gas phase at MP2/6-31+G(d) level

\begin{tabular}{|l|c|c|c|c|}
\hline \multirow{2}{*}{ Reactants } & \multicolumn{4}{|c|}{$\mathrm{NCC} \equiv \mathrm{CCN}$} \\
\cline { 2 - 5 } & $\Delta D_{\text {diene }}^{\ddagger}$ & $\Delta D^{\ddagger}$ ABN & $\Delta G^{\ddagger}$ & $\Delta S^{\ddagger}$ \\
\hline benzene + ABN & 25.1 & 20.9 & 35.7 & 10.3 \\
\hline naphthalene + ABN & 20.2 & 18.4 & 26.4 & 12.2 \\
\hline anthracene + ABN & 12.2 & 14.8 & 12.3 & 14.7 \\
\hline
\end{tabular}

The relationship of deformation energy with resonance energy of the aromatic system is very clear from the data. The deformation energy of the aromatic unit decreased with the resonance energy just as the deformation energy of the dienophile decreased with the deformation energy of the aromatic unit. In other words, more the aromatic character, more is the deformation energy of each reactant in the required effort to perturb each other to cause an effective orbital interaction.

In view of the above expected results, it was felt necessary to explore whether a similar relationship existed in DA reactions of the five-ring heterocycles. The relevant data for DA reactions with acetylene-1,2-bisnitrile is collected in Table $11 \mathrm{a}$. 
Table 11a. Deformation free energies $\left(\Delta D^{\ddagger}, \mathrm{kcal} / \mathrm{mol}\right)$ and stabilization free energies $\left(\Delta S^{\ddagger}, \mathrm{kcal} / \mathrm{mol}\right)$ in the TS structures for DA reactions of pyrrole, furan, thiophene, and selenophene with acetylene-1,2-bisnitrile $(\mathrm{ABN})$ in gas phase at MP2/6-31+G(d) level

\begin{tabular}{|l|c|c|c|c|}
\hline \multirow{2}{*}{ Heterocycle } & \multicolumn{4}{|c|}{$\mathrm{NCC} \equiv \mathrm{CCN}(\mathrm{ABN})$} \\
\cline { 2 - 5 } & $\Delta D^{\ddagger}$ heterocycle & $\Delta D^{\ddagger}{ }_{\mathrm{ABN}}$ & $\Delta G^{\ddagger}$ & $\Delta S^{\ddagger}$ \\
\hline pyrrole & 22.2 & 21.0 & 25.1 & 18.1 \\
\hline furan & 17.9 & 17.5 & 23.9 & 11.5 \\
\hline thiophene & 22.40 & 18.9 & 30.7 & 22.4 \\
\hline Selenophene & 22.36 & 17.9 & 23.1 & 17.2 \\
\hline
\end{tabular}

$\Delta S E^{\ddagger}=\Delta D E^{\ddagger}$ heterocycle $+\Delta D E^{\ddagger} \mathrm{ABN}-\Delta G^{\ddagger}$

Following the deformation energy of the five-ring heterocycle, the resonance energy follows the order thiophene $\geq$ selenophene $\geq$ pyrrole $>$ furan. However, following the deformation energy of the dienophile, the resonance energy follows the order pyrrole $>$ thiophene $>$ selenophene $\geq$ furan. The discrepancy is obvious because the orders are not the same as for benzene, naphthalene and anthracene. The deformation energy approach is not applicable to the five-ring heterocycles. The different heteroatoms allow different flexibility and, hence, deformity during the progress of the reaction.

We wished to confirm the above deformation energy results by studying endo-DA reactions of five-ring heterocycles with MA. The heteroatom in the endo-TS structure affects the reaction by impacting the electronics of the diene system but not directly as it may possibly happen in the exoTS structure. The deformation and activation free energy data are collected in Table 11b. The aromaticity order is pyrrole $>$ selenophene $>$ thiophene $>$ furan from the deformation energies of heterocycles and pyrrole $>$ thiophene $>$ furan $>$ selenophene from the deformation energies of dienophile. Other than pyrrole being on the top of the aromaticity order, nothing else is certain.

We noticed above different reactivity profiles and, hence, aromaticity orders from the use of different dienophiles. The deformation energy approach may, therefore, not be used with confidence to the assessment of reactivity order and, hence, the relative aromaticity of five-ring heterocycles. 
Table 11b. Deformation free energies $\left(\Delta D^{\ddagger}, \mathrm{kcal} / \mathrm{mol}\right)$ and stabilization free energies $\left(\Delta S^{\ddagger}, \mathrm{kcal} / \mathrm{mol}\right)$ in the TS structures for endo DA reactions of pyrrole, furan, thiophene, and selenophene with MA in gas phase at $\mathrm{MP} 2 / 6-31+\mathrm{G}(\mathrm{d})$ level

\begin{tabular}{|l|c|c|c|c|}
\hline \multirow{2}{*}{ Reactants } & \multicolumn{4}{|c|}{ MA } \\
\cline { 2 - 5 } & $\Delta D^{\ddagger}$ heterocycle & $\Delta D^{\ddagger}$ MA & $\Delta G^{\ddagger}$ & $\Delta S^{\ddagger}$ \\
\hline pyrrole & 25.2 & 17.0 & 24.2 & 18.0 \\
\hline furan & 19.6 & 12.9 & 20.4 & 12.1 \\
\hline thiophene & 23.8 & 13.7 & 27.1 & 10.4 \\
\hline Selenophene & 24.7 & 12.2 & 21.1 & 15.8 \\
\hline
\end{tabular}

$$
\Delta S E^{*}=\Delta D E^{\sharp} \text { heterocycle }+\Delta D E^{*} \mathrm{MA}-\Delta G^{\ddagger}
$$

(10) DA reactions of thiophene-1,1-dioxide with MA: Unlike thiophene, thiophene-1,1-dioxide reacts with MA in DA fashion under the usual thermal conditions. The resonance stabilization due to mixing of sulfur lone pair with the ring $\pi$ bonds is no doubt lost on oxidation of sulfur and the molecule begins to behave like a normal cyclic 1,3-diene and its reactivity is enhanced. The difference in reactivity of this molecule and cyclopentadiene must, therefore, emanate from two sources: (a) $R$ and (b) the allylic interactions, i.e., the interactions of the ring $\pi$ bonds with C5substituents.

TABLE 12. $R$ and $\pi$ bond distances $(\AA)$ in the endo- and exo-TS structures for DA reactions of cyclopentadiene $\left(\mathrm{Y}=\mathrm{CH}_{2}\right)$, thiophene $(\mathrm{Y}=\mathrm{S})$ and thiophene- $S, S$-dioxide $\left(\mathrm{Y}=\mathrm{SO}_{2}\right)$ with MA, activation energies $\left(\Delta G^{\ddagger}, \mathrm{kcal} / \mathrm{mol}\right)$ and enthalpy changes $(\Delta G, \mathrm{kcal} / \mathrm{mol})$ from gas phase calculations at MP2/6$31+\mathrm{G}(\mathrm{d})$ level

\begin{tabular}{|l|c|c|c|c|c|c|c|c|}
\hline \multirow{2}{*}{ Diene } & \multicolumn{4}{|c|}{ endo-TS } & \multicolumn{4}{c|}{ exo-TS } \\
\cline { 2 - 9 } & $R$ & $\pi$ & $\Delta G^{\ddagger}$ & $\Delta G$ & $\mathrm{R}$ & $\pi$ & $\Delta G^{\ddagger}$ & $\Delta G$ \\
\hline $\mathrm{Y}=\mathrm{CH}_{2}$ & 2.3213 & 1.3890 & 12.0 & -18.6 & 2.3221 & 1.3905 & 14.7 & -18.5 \\
\hline $\mathrm{Y}=\mathrm{S}$ & 2.3979 & 1.4150 & 27.1 & +2.3 & 2.3958 & 1.4152 & 28.7 & +2.1 \\
\hline $\mathrm{Y}=\mathrm{SO}_{2}$ & 2.5343 & 1.3816 & 14.7 & -30.7 & 2.5338 & 1.3849 & 24.4 & -27.1 \\
\hline
\end{tabular}


The relevant parameters for the DA reactions of cyclopentadiene, thiophene and thiophene-1,1dioxide are collected in Table 12. The larger $R$ in the TS structure for the reaction of thiophene1,1-dioxide must ensure higher activation energy in keeping with the present findings.

The $\sigma_{\mathrm{C} 5-\mathrm{H}-} \pi^{*}$ ring and $\pi_{\text {ring }}-\sigma^{*}{ }_{\mathrm{C} 5-\mathrm{H}}$ interactions in the reaction of cyclopentadiene with MA are, respectively, 15.9 and $9.3 \mathrm{kcal} / \mathrm{mol}$ in the endo-TS structure. The net $\sigma_{\mathrm{C} 5-\mathrm{H}}-\pi^{*}$ ring interaction therefore is $6.6 \mathrm{kcal} / \mathrm{mol}$ and its role is to impart aromatic character to the ring and, thus, raise the energy of activation. Likewise, the $\sigma_{\mathrm{S}-\mathrm{O}}-\pi^{*}$ ring and $\pi_{\text {ring }}-\sigma^{*}$ S-O interactions in the reaction of thiophene-1,1-dioxide with MA are, respectively, 1.9 and $12.9 \mathrm{kcal} / \mathrm{mol}$ in the endo-TS structure. The net $\pi_{\text {ring }}-\sigma^{*}$ s-o interaction, therefore, is $11.0 \mathrm{kcal} / \mathrm{mol}$ and its role would be to impart antiaromatic character to the ring and, thus, lower the energy of activation. If the $R$-effect is ignored, for the time being, the activation energy of thiophene-1,1-dioxide would be expected to be lower than that of cyclopentadiene. However, it is not so. The activation energy of thiophene-1,1-dioxide is $2.7 \mathrm{kcal} / \mathrm{mol}$ higher than that of cyclopentadiene. More than $2.7 \mathrm{kcal} / \mathrm{mol}$ energy will be required to accommodate $R$-effect in allowing thiophene-1,1-dioxide to react.

The $\sigma_{\mathrm{C} 5-\mathrm{H}^{-}} \pi^{*}$ ring and $\pi_{\text {ring }}-\sigma^{*}{ }_{\mathrm{C} 5-\mathrm{H}}$ interactions in the exo-TS structure for reaction of cyclopentadiene with MA are, respectively, 17.8 and $8.4 \mathrm{kcal} / \mathrm{mol}$. The net $\sigma_{\mathrm{C} 5-\mathrm{H}-} \pi^{*}$ ring interaction, therefore, is $9.4 \mathrm{kcal} / \mathrm{mol}$ and it will impart aromatic character to the ring and raise the activation energy. Similarly, the $\sigma_{\mathrm{S}-\mathrm{O}}-\pi^{*}$ ring and $\pi_{\text {ring }}-\sigma^{*}$ S-O interactions in the exo-TS structure for the reaction of thiophene-1,1-dioxide with MA are, respectively, 1.9 and $13.0 \mathrm{kcal} / \mathrm{mol}$. The net $\pi_{\text {ring }}-\sigma^{*} \mathrm{~S}-\mathrm{O}$ interaction is $11.1 \mathrm{kcal} / \mathrm{mol}$ and it would impart anti-aromatic character to the ring and lower the activation energy. However, the activation energy of the reaction of thiophene-1,1-dioxide is 9.7 $\mathrm{kcal} / \mathrm{mol}$ higher than that of cyclopentadiene. The $R$-effect must contribute a large part of this higher energy demand.

Similar to thiophene-1,1-dioxide, one may expect the presence of $1 p_{\mathrm{S}}-\pi^{*}{ }_{\text {ring }}$ and $\pi_{\text {ring }}-1 \mathrm{p}^{*}{ }_{\mathrm{S}}\left(\mathrm{lp}_{\mathrm{S}}=\right.$ lone pair of S) interactions in the TS structures for reaction of thiophene with MA. However, these interactions are absent in both the endo- and exo-TS structures. In such a situation, the activation energy will depend on $R$, among other factors, and it will be expected to rise from cyclopentadiene to thiophene. Indeed, the activation energy for the reaction of thiophene is a substantial 14-15 $\mathrm{kcal} / \mathrm{mol}$ above cyclopentadiene. 
It is important to note that interactions of the sorts $1 \mathrm{p}_{\mathrm{X}}-\pi^{*}{ }_{\text {ring }}$ and $\pi_{\text {ring }}-1 \mathrm{p}^{*} \mathrm{x}\left(\mathrm{lp}_{\mathrm{X}}=\right.$ heteroatom lone pair) are also completely absent in the endo- and exo-TS structures for reactions of pyrrole, furan and selenophene with MA. The interaction $\sigma_{\mathrm{N}-\mathrm{H}-} \pi^{*}$ ring is absent in the reaction of pyrrole. The absence of $1 p_{X}-\pi^{*}$ ring interaction in the DA reactions of the five-ring heterocycles clearly suggests that their aromatic characters are fully lifted in the TS structures. On account of ground state aromaticity ensuring planar structures, sufficient energy is required for structure deformation to assume the TS structure.

The activation energy drops from $27.1 \mathrm{kcal} / \mathrm{mol}$ for endo addition of thiophene to MA to 14.7 $\mathrm{kcal} / \mathrm{mol}$ for thiophene-1,1-dioxide, which is closer to $12.0 \mathrm{kcal} / \mathrm{mol}$ as the activation energy of cyclopentadiene. This drop in activation energy of thiophene-1,1-dioxide from that of thiophene arises from the anti-aromatic character introduced by the net of $\sigma_{\mathrm{S}-\mathrm{O}-} \pi^{*}$ ring and $\pi_{\text {ring }}-\sigma^{*} \mathrm{~S}-\mathrm{O}$ interactions in the dioxide.

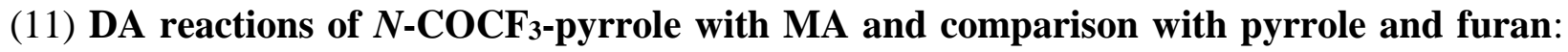

We considered $N$-trifluoroacetylation of pyrrole to disengage the lone pair from interaction with ring $\pi$-bonds in the ground state structure and study its DA reaction with MA to estimate activation energy and compare it with those of furan and the parent pyrrole. Since the $1 p-\pi *^{*}$ ring interaction is also lifted in the TS structure, the role of activation energy is simply to deform the structure to disrupt the lone pair conjugation and, thereby, confer normal diene character to the heterocycle for reaction in DA manner. $N$-trifluoroacetylation was, therefore, expected to lower the activation energy to a level where it may match with that of furan, but for the differences in $R$ in the TS structures. This argument will probably not be applicable to exo-TS structure because of the apparent steric interactions arising from the $\mathrm{COCF}_{3}$ group.

The TS data is collected in Table 13. Indeed, the activation energy drops from pyrrole to $\mathrm{N}-\mathrm{COCF}_{3}-$ pyrrole by $3.2 \mathrm{kcal} / \mathrm{mol}$ and it is now only $0.6 \mathrm{kcal} / \mathrm{mol}$ above furan. We must note that $R$ is also a bit longer in $\mathrm{N}-\mathrm{COCF}_{3}$-pyrrole than in furan. The R-hypothesis appears vindicated. 
Table 13. $R$ and $\pi$ bond distances $(\AA)$ in the endo-TS structures for DA reactions of pyrrole, $N-\mathrm{COCF}_{3}-$ pyrrole, and furan with MA, activation energies $\left(\Delta G^{\ddagger}, \mathrm{kcal} / \mathrm{mol}\right)$ and enthalpy changes $(\Delta G, \mathrm{kcal} / \mathrm{mol})$ from gas phase calculations at MP2/6-31+G(d) level

\begin{tabular}{|c|c|c|c|c|}
\hline \multirow{2}{*}{ Diene } & \multicolumn{4}{|c|}{ endo-TS } \\
\cline { 2 - 5 } & $R$ & $\pi$ & $\Delta G^{\ddagger}$ & $\Delta G$ \\
\hline pyrrole & 2.2000 & 1.4261 & 24.2 & 8.4 \\
\hline$N$-COCF 3 -pyrrole & 2.2374 & 1.4160 & 21.0 & 1.3 \\
\hline furan & 2.1601 & 1.4122 & 20.4 & 0.8 \\
\hline
\end{tabular}

TABLE 14. Study of the effects of solvents on the activation free energies $\left(\Delta G^{\sharp}\right)$ of the endo- and exo-DA reactions of pyrrole, furan, thiophene and selenophene with MA and enthalpy changes $(\Delta G, \mathrm{kcal} / \mathrm{mol})$ at the MP2/6-311++G(d,p) level

\begin{tabular}{|c|c|c|c|c|}
\hline \multirow[b]{2}{*}{ Diene-Solvent } & \multicolumn{2}{|c|}{ endo-TS } & \multicolumn{2}{|c|}{ exo-TS } \\
\hline & $\Delta G^{\ddagger}$ & $\Delta G$ & $\Delta G^{\ddagger}$ & $\Delta G$ \\
\hline Pyrrole- $\mathrm{CH}_{3} \mathrm{CN}$ & 22.04 & 9.66 & 22.14 & 7.04 \\
\hline Pyrrole-Et ${ }_{2} \mathrm{O}$ & 22.32 & 9.05 & 21.90 & 6.73 \\
\hline Pyrrole- $\mathrm{CHCl}_{3}$ & 22.30 & 9.12 & 21.93 & 6.77 \\
\hline Furan- $\mathrm{CH}_{3} \mathrm{CN}$ & 18.33 & 0.37 & 18.16 & -2.13 \\
\hline Furan- $\mathrm{Et}_{2} \mathrm{O}$ & 18.40 & 0.25 & 18.49 & -1.98 \\
\hline Furan- $\mathrm{CHCl}_{3}$ & 18.39 & 0.26 & 18.46 & -1.99 \\
\hline Thiophene- $\mathrm{CH}_{3} \mathrm{CN}$ & 24.56 & 1.57 & 25.31 & 0.31 \\
\hline Thiophene- $\mathrm{Et}_{2} \mathrm{O}$ & 24.60 & 1.37 & 25.56 & 0.36 \\
\hline Thiophene- $\mathrm{CHCl}_{3}$ & 24.60 & 1.40 & 25.54 & 0.36 \\
\hline Selenophene- $\mathrm{CH}_{3} \mathrm{CN}$ & 24.91 & -2.07 & 26.29 & -2.69 \\
\hline Selenophene- $\mathrm{Et}_{2} \mathrm{O}$ & 24.91 & -2.30 & 26.52 & -2.69 \\
\hline Selenophene- $\mathrm{CHCl}_{3}$ & 24.91 & -2.27 & 26.50 & -2.69 \\
\hline
\end{tabular}

Having studied the total reaction profiles, we considered it desirable to comment on the stereoselectivity of DA reactions of five-ring heterocycles with maleic anhydride. For all but 
pyrrole, endo-addition is kinetically favored over the exo-addition. However, on including the enthalpy change (endergonic/exergonic character) of the processes and also allowing for the imminent reaction equilibration, all the heterocycles except selenophene are predicted for exo selectivity. Using the results in Table 1a and the results of solvent study collected in Table 14, the reaction profiles are depicted in Figure 4.

The analysis of data in detail is as follows:

(a) Both the endo- and exo-additions of pyrrole are endergonic and, hence, the reversal is eminent. The differential activation energy $\left(\Delta \Delta G^{\ddagger}\right)$ of the reverse reactions is, therefore, more important than those of the forward reactions. Since the reverse reactions are very similar in their activation energies for differing merely by $0.1 \mathrm{kcal} / \mathrm{mol}$ from each other, a mixture of products is predicted. The $\Delta \Delta G^{\ddagger}$ for the reverse processes, however, is raised to $2.0 \mathrm{kcal} / \mathrm{mol}$ in chloroform as solvent. The reversal of the exo-adduct is slower than endoadduct. The exo-adduct will therefore accumulate and constitute the major product. The situation remains much the same in solvent ether and also acetonitrile. Specifically, the $\Delta \Delta G^{\ddagger}$ for the reverse processes are $1.9 \mathrm{kcal} / \mathrm{mol}$ in ether and $2.7 \mathrm{kcal} / \mathrm{mol}$ in acetonitrile. The largest $\Delta \Delta G^{\ddagger}$ in acetonitrile is expected to best promote formation of the exo adduct among the solvents investigated herein. The results of the solvent effect on DA reactions of five-ring heterocycles are collected in Table 8.

(b) The energy requirement for endo addition of furan is the same as for the reverse reaction. The exo-addition is $0.5 \mathrm{kcal} / \mathrm{mol}$ higher than endo-addition and also the reversal of the exoadduct is $2.2 \mathrm{kcal} / \mathrm{mol}$ more difficult than that of the endo adduct. Consequently, under thermal conditions allowing exo-addition, it is predicted to constitute the major pathway. In acetonitrile, kinetics favors exo- over endo-addition by $0.2 \mathrm{kcal} / \mathrm{mol}$. Reversal of the endo-adduct is faster than its formation by $0.4 \mathrm{kcal} / \mathrm{mol}$ and, hence, it must not accumulate. In contrast, reversal of the exo-adduct is $2.1 \mathrm{kcal} / \mathrm{mol}$ more difficult than its formation, allowing it to accumulate and constitute the predominant product. The overall scenario remains unchanged in solvents ether and chloroform. ${ }^{37}$

(c) The exo-addition of thiophene is less endergonic than endo-addition by $0.5 \mathrm{kcal} / \mathrm{mol}$. Further, since the reversal of the endo-process is faster than forward process by 0.9 $\mathrm{kcal} / \mathrm{mol}$, the endo-product will not accumulate. The reversal of the exo-process is also 
faster than the forward process but by only $0.3 \mathrm{kcal} / \mathrm{mol}$. Thus, under the reaction conditions that both the endo $\left(\Delta G^{\ddagger}=24.6 \mathrm{kcal} / \mathrm{mol}\right)$ and exo $\left(\Delta G^{\ddagger}=26.0 \mathrm{kcal} / \mathrm{mol}\right)$ processes could take place, the exo-process will predominate. Except for small changes in kinetics, overall scenario remains unchanged in ether, acetonitrile and chloroform.
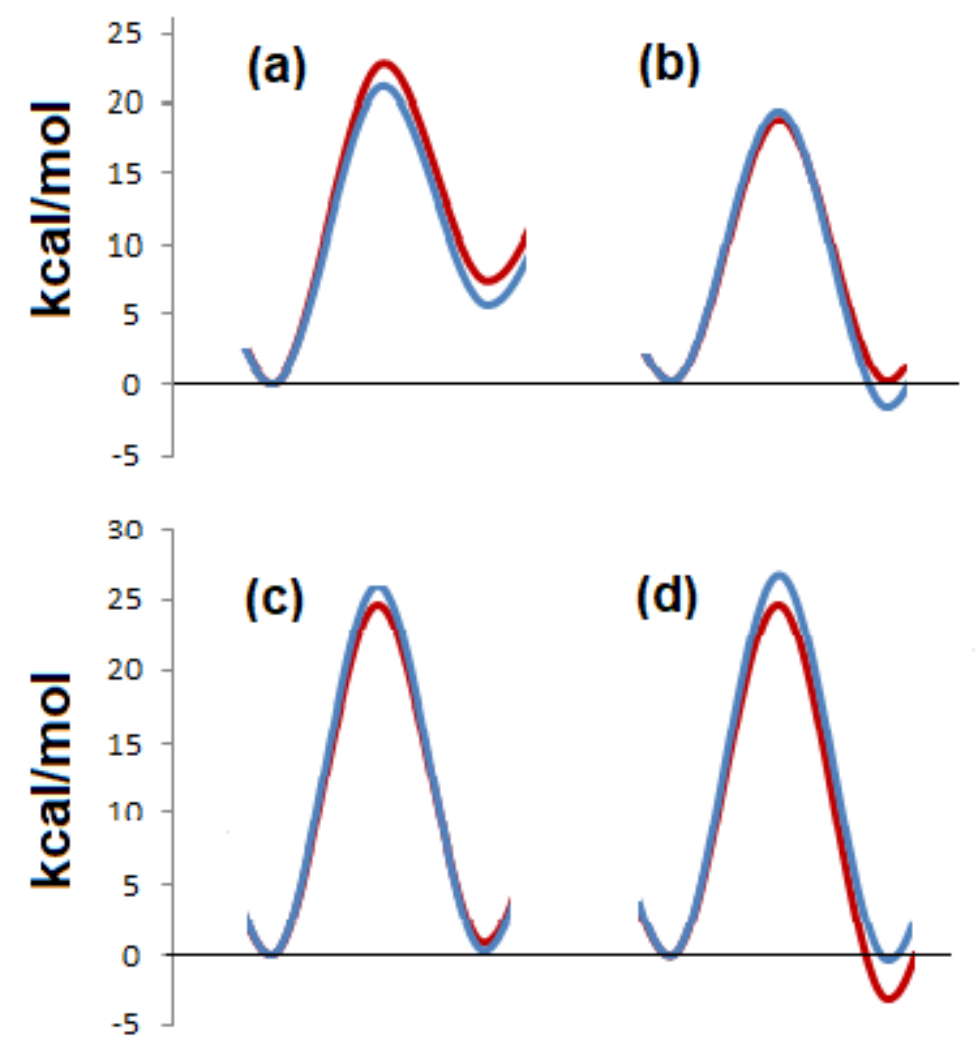

Figure 4. The reaction profiles for the endo (red line) and exo (blue line) Diels-Alder reactions of maleic anhydride with (a) pyrrole, (b) furan, (c) thiophene and (d) selenophene at the MP2/6$311++\mathrm{G}(\mathrm{d}, \mathrm{p})$ level

(d) The exo-addition of thiophene is less endergonic than endo-addition by $0.5 \mathrm{kcal} / \mathrm{mol}$. Further, since the reversal of the endo-process is faster than forward process by 0.9 $\mathrm{kcal} / \mathrm{mol}$, the endo-product will not accumulate. The reversal of the exo-process is also faster than the forward process but by only $0.3 \mathrm{kcal} / \mathrm{mol}$. Thus, under the reaction conditions that both the endo $\left(\Delta G^{\ddagger}=24.6 \mathrm{kcal} / \mathrm{mol}\right)$ and exo $\left(\Delta G^{\ddagger}=26.0 \mathrm{kcal} / \mathrm{mol}\right)$ 
processes could take place, the exo-process will predominate. Except for small changes in kinetics, overall scenario remains unchanged in ether, acetonitrile and chloroform.

(e) Both the endo $\left(\Delta G^{\ddagger}=24.8 \mathrm{kcal} / \mathrm{mol}\right)$ and exo $\left(\Delta G^{\ddagger}=26.9 \mathrm{kcal} / \mathrm{mol}\right)$ additions of selenophene are exergonic by 2.9 and $0.3 \mathrm{kcal} / \mathrm{mol}$, respectively. Since $\Delta G^{\ddagger}$ for the reverse processes $\left(\Delta G^{\ddagger}\right.$ endo-adduct $=27.7 \mathrm{kcal} / \mathrm{mol}$ and $\Delta G^{\ddagger}$ exo-adduct $\left.=27.2 \mathrm{kcal} / \mathrm{mol}\right)$ are larger than the corresponding forward processes, the reaction is expected to proceed under kinetic control to allow the endo-adduct predominate. The scenario remains unchanged in ether, acetonitrile and chloroform.

Experimentally, pyrrole is reported to undergo DA reaction with maleic anhydride to furnish a mixture (composition not determined) of the adducts, ${ }^{38}$ and both furan ${ }^{39}$ and thiophene ${ }^{20}$ the exoadducts largely. Since the DA adduct formed from selenophene undergoes rapid extrusion of selenium, it prevents comment on the endo/exo selectivity. ${ }^{22}$

\section{CONCLUSIONS}

The order of aromaticity predicted on account of the difficulty of DA reaction and also on account of AIBIC is selenophene > thiophene > pyrrole > furan. This order, however, is pyrrole > > furan $>$ thiophene $>$ selenophene on account of $1 \mathrm{p} \rightarrow \pi_{\mathrm{C}=\mathrm{C}}$ interaction in the ground state structures. The use of relative DA reactivity as the marker of aromaticity is not appropriate because the reactivity changes substantially with the change in the separation of the termini of the diene for reaction with a given dienophile. A distance larger than $\pi$ bond of the dienophile lifts the collinearity of the requisite $p$ orbitals required for $\sigma$ bond formation and the activation energy is raised.

Having considered aromaticity as the sole factor for the control of reactivity, one will predict very similar reactivity profiles for both furan and thiophene $\left(\mathrm{l} p \rightarrow \pi^{*} \mathrm{C}=\mathrm{C}=42.9 \mathrm{kcal} / \mathrm{mol}\right.$ in furan and $41.9 \mathrm{kcal} / \mathrm{mol}$ in thiophene). However, thiophene reacts only under forcing conditions. This is due to the difference in the distances between the reacting termini of the diene; the substantially large distance in thiophene results in significantly poor collinearity of the terminal $p$ orbitals.

The endo/exo-selectivities predicted from the combination of differential TS structure energies for

forward and reverse reactions and also the enthalpy changes are in excellent agreement with experiments. Among five-ring heterocycles, while furan and thiophene furnish exo-adducts, 
selenophene is predicted for endo- and pyrrole for exo-addition, depending upon the reaction conditions. Solvents may change the kinetics and also the course of the reaction.

\section{ASSOCIATED CONTENT \\ Supporting Information (SI)}

Cartesian coordinates and Gibbs' free energies of the optimized substrates, products and the transition state structures (PDF, 84 pages).

\section{AUTHOR INFORMATION}

\section{Corresponding Author}

Veejendra K. Yadav - Department of Chemistry, Indian Institute of Technology Kanpur, Kanpur 208016, India; orcid.org/0000-0001-8294-0677; E-mail: vijendra@iitk.ac.in

\section{ACKNOWLWDGEMENTS}

The author acknowledges Computer Centre, IIT Kanpur for allocation of time on HPC series of supercomputers.

\section{REFERENCES AND NOTES}

(1) Minkin, V. I.; Glukhovtsev, M. N.; Simkin, B. Y. Aromaticity and Antiaromaticity. Wiley, New York (1994).

(2) Dey, S.; Manogaran, D.; Manogaran, S.; Schaefer III, H. F. Quantification of Aromaticity of Heterocyclic Systems Using Interaction Coordinates. J. Phys. Chem. A 2018, 122, 6953-6960.

(3) (a) Horner, K. E.; Karadakov, P. B. Shielding in and around Oxazole, Imidazole, and Thiazole: How Does the Second Heteroatom Affect Aromaticity and Bonding? J. Org. Chem. 2015, 80, 7150-7157. (b) Horner, K. E.; Karadakov, P. B. Chemical Bonding and Aromaticity in Furan, Pyrrole, and Thiophene: A Magnetic Shielding Study. J. Org. Chem. 2013, 78, 8037-8043. (c) Schleyer, P. v. R.; Maerker, C.; Dransfeld, A.; Jiao, H.; Homes, N. J. R. v. E. Nucleus-Independent Chemical Shifts: A Simple and Efficient Aromaticity Probe. J. Am. Chem. Soc. 1996, 118, 6317-6318. 
(4) (a) Aihara, J. A new definition of Dewar-type resonance energies. J. Am. Chem. Soc. 1976, 98, 2750-2758. (b) Gutman, I.; Milun, M.; Trinajstic, N. Graph theory and molecular orbitals. 19. Nonparametric resonance energies of arbitrary conjugated systems. J. Am. Chem. Soc. 1977, 99, 1692-1704.

(5) Aihara, J.; Kanno, H.; Ishida, T. Magnetic Resonance Energies of Heterocyclic Conjugated Molecules. J. Phys. Chem. A 2007, 111, 8873-8876.

(6) Aihara, J. Circuit Resonance Energy: A Key Quantity That Links Energetic and Magnetic Criteria of Aromaticity. J. Am. Chem. Soc. 2006, 128, 2873-2879.

(7) (a) Arkin, R.; Kerim, A. A study on the aromaticity and magnetotropicity of $10 \pi$-electron azapentalene derivatives. Chem. Phys. Lett. 2012, 546, 144-149. (b) Aihara, J. Spherical Aromaticity in Fullerenes and the Nucleus-Indpendent Chemical Shifts at the Cage Centers. Bull. Chem. Soc. Jpn. 2003, 76, 103-105. (c) Poater, J.; Garcia-Cruz, I.; Illas, F.; Sola, M. Discrepancy between common local aromaticity measures in a series of carbazole derivatives. Phys. Chem. Chem. Phys. 2004, 6, 314-318. (d) Stanger, A. What is... aromaticity: a critique of the concept of aromaticity-can it really be defined? Chem. Commun. 2009, 15, 1939-1947. (e) Omelchenko, I. V.; Shishkin, O. V.; Gorb, L.; Leszczynski, J.; Fiase, S.; Bultinck, P. Aromaticity in heterocyclic analogues of benzene: comprehensive analysis of structural aspects, electron decolalization and magnetic characteristics. Phys. Chem. Chem. Phys. 2011, 13, 20536-20548. (f) Islas, R.; Martinez-Guajardo, G.; Jimenez-Halla, J. O. C.; Sola, M.; Merino, G. Not All That Has a Negative NICS Is Aromatic: The case of the H-bonded Cyclic Trimer of HF. J. Chem. Theory Comput. 2010, $6,1131-1135$.

(8) For criticism of the NICS approach, see: (a) Lazzeretti, P. Assesment of aromaticity via molecular response properties. Phys. Chem. Chem. Phys. 2004, 6, 217-223. (b) Fias, S.; Fowler, P. W.; Delgado, J. L.; Hahn, U.; Bultinck, P. Correlation of Delocalization Indices and Current-Density Maps in Polyclic Aromatic Hydrocarbons. Chem.-Eur. J. 2008, 14, 3093-3099. For comments on the reliability of other approaches for aromaticity prediction, see: (c) Najmidin, K.; Kerim, A.; Abdirishit, P.; Kalam, H.; Tawar, T. A comparative study of the aromaticity of pyrrole, furan, thiophene, and their aza-derivatives. J. Mol. Model. 2013, 19, 3529-3535.

(9) Feixas, F.; Matito, E.; Poater, J.; Sola, M. On the performance of some aromaticity indices: A critical assessment using a test set. J. Comput. Chem. 2008, 29, 1543-1554.

(10) (a) Hückel, E. Quantentheoretische Beiträge zum Benzolproblem I. Die Elektronenkonfiguration des Benzols und verwandter Verbindungen. Z. Phys. 1931, 70, 204-286. (b) Hückel, E. Quanstentheoretische Beiträge zum Benzolproblem II. Quantentheorie der induzierten Polaritäten. Z. Phys. 1931, 72, 310-337. (c) Hückel, E. Quantentheoretische Beiträge zum Problem der aromatischen und ungesättigten Verbindungen. III". Z. Phys. 1932, 76, 628-648. (d) Doering, W. v. E.; Detert. F. L. Cycloheptatrienylium Oxide. J. Am. Chem. Soc. 1951, 73, 876-877. 
(11) (a) Kruszewski, J.; Krygowski, T. M. Definition of aromaticity basing on the harmonic oscillator model. Tetrahedron Lett. 1972, 13, 3839-3842. (b) Krygowski, T. M. Crystallographic studies of inter- and intramolecular interactions reflected in aromatic character of .pi.-electron systems. J. Chem. Inf. Comput. Sci. 1993, 33, 70-78.

(12) (a) Islas, R.; Heine, T.; Merino, G. The Induced Magnetic Field. Acc. Chem. Res. 2012, 45, 215-228. (b) Poater, J.; Duran, M.; Sola, M.; Silvi, B. Theoretical Evaluation of Electron Delocalization in Aromatic Molecules by Means of Atoms in Molecules (AIM) and Electron Localization Function (ELF) Topological Approaches. Chem. Rev. 2005, 105, 3911-3947. (c) Chen, Z. F.; Wannere, C. S.; Corminboeuf, C.; Puchta, R.; Schleyer, P. v. R. Nucleus-Independent Chemical Shifts (NICS) as an Aromaticity Criterion. Chem. Rev. 2005, 10, 3842-3888. (d) Merino, G.; Vela, A.; Heine, T. Description of Electron Delocalization via the Analysis of Molecular Fields. Chem. Rev. 2005, 105, 38123841 (e) Lazzeretti, P. Ring currents. Prog. Nucl. Magn. Reson. Spectrosc. 2000, 36, 1-88.

(13) Doddi, G.; Illuminati, G.; Mencarelli, P.; Stegel, F. Nucleophilic Substitution at the Pyrrole Ring. Comparison with Furan, Thiophene, and Benzene Rings in Piperidinodenitration. J. Org. Chem. 1976, 41, 2824-2826.

(14) G. Marino, G. Electrophilic Substitutions of Five-Membered Rings. Adv. Heterocycl. Chem. 1971, 13, $235-314$.

(15) The Chemistry of the Aromatic Heterocycles, Chapter 25, p 1228. https://www.saplinglearning.com/media/loudon/loudon5ech25sec03.pdf

(16) Belen'kii, L. I.; Suslov, I. A.; Chuvylkin, N. D. Substrate and Positional Selectivity in Electrophilic Substitution Reactions of Pyrrole, Furan, Thiophene, and Selenophene Derivatives. Chem. of Heterocycl. Compd. 2003, 39, 3648; and references cited therein.

(17) Baran, P.; Richter, J. R. https://www.scripps.edu/baran/heterocycles/Essentials1-2009.pdf

(18) The chemical shifts are for the neat liquids with only a small amount of TMS added as a standard. See: Page, Jr., T. F.; Alger, T.; D. M. Grant, D. M. The Carbon-13 Nuclear Magnetic Resonance Spectra of Furan, Pyrrole, Thiophene, and Some of Their Methyl Derivatives. J. Am. Chem. Soc. 1965, 87, 5333-5339.

(19) Dauben, W. G.; Krabbenhoft, H. O. Organic reactions at high pressure. Cycloadditions with furans. J. Am. Chem. Soc. 1976, 98, 1992-1993.

(20) (a) Kotsuki, H.; Kitagawa, S.; Nishizawa, H.; Tokoroyama, T. High pressure organic chemistry. 2. Diels-Alder reaction of thiophene with maleic anhydride at very high pressure. J. Org. Chem. 1978, 43, 1471-1472. (b) Kotsuki, H.; Nishizawa, H.; Kitagawa, S.; Ochi, M.; Yamasaki, N.; Matsuoka, K.; Tokoroyama, T. High Pressure Organic Chemistry. III. Diels-Alder reaction of Thiophene with Maleic Anhydride. Bull. Chem. Soc. Jpn. 1979, 52, 544-548. 
(21) K. Kumamoto, I. Fukada, H. Kotsuki, Diels-Alder Reaction of Thiophene: Dramatic Effects of HighPressure/Solvent-Free Conditions Angew. Chem. Int. Ed. 2004, 43, 2015-2017.

(22) Bird, C. W.; Cheeseman, G. W. H.; Hörnfeldt, A.-B. in Comprehensive Heterocyclic Chemistry, 1984, Elsevier, Editors: Katrizky, A. R.; Rees, C. W. https://doi.org/10.1016/B978-008096519-2.00066-7

(23) Gaussian 16, Revision C.01, Frisch, M. J.; Trucks, G. W.; Schlegel, H. B.; Scuseria, G. E.; Robb, M. A.; Cheeseman, J. R.; Scalmani, G.; Barone, V.; Petersson, G. A.; Nakatsuji, H.; Li, X.; Caricato, M.; Marenich, A. V.; Bloino, J.; Janesko, B. G.; Gomperts, R.; Mennucci, B.; Hratchian, H. P.; Ortiz, J. V.; Izmaylov, A. F.; Sonnenberg, J. L.; Williams-Young, D.; Ding, F.; Lipparini, F.; Egidi, F.; Goings, J.; Peng, B.; Petrone, A.; Henderson, T.; Ranasinghe, D.; Zakrzewski, V. G.; Gao, J.; Rega, N.; Zheng, G.; Liang, W.; Hada, M.; Ehara, M.; Toyota, K.; Fukuda, R.; Hasegawa, J.; Ishida, M.; Nakajima, T.; Honda, Y.; Kitao, O.; Nakai, H.; Vreven, T.; Throssell, K.; Montgomery, J. A., Jr.; Peralta, J. E.; Ogliaro, F.; Bearpark, M. J.; Heyd, J. J.; Brothers, E. N.; Kudin, K. N.; Staroverov, V. N.; Keith, T. A.; Kobayashi, R.; Normand, J.; Raghavachari, K.; Rendell, A. P.; Burant, J. C.; Iyengar, S. S.; Tomasi, J.; Cossi, M.; Millam, J. M.; Klene, M.; Adamo, C.; Cammi, R.; Ochterski, J. W.; Martin, R. L.; Morokuma, K.; Farkas, O.; Foresman, J. B.; Fox, D. J. Gaussian, Inc., Wallingford CT, 2016.

(24) (a) Barone, V.; Cossi, M. Quantum Calculation of Molecular Energies and Energy Gradients in Solution by a Conductor Solvent Model. J. Phys. Chem. A 1998, 102, 1995-2001. (b) Cossi, M.; Rega, N.; Scalmani, G.; Barone, V. Energies, structures, and electronic properties of molecules in solution with the C-PCM model. J. Comput. Chem. 2003, 24, 669-681.

(25) Reed, A. E.; Curtiss, L. A.; Weinhold, F. Intermolecular interactions from natural bond orbital, donor-acceptor viewpoint. Chem. Rev. 1988, 88, 899-926.

(26) (a) Nyulászi, L.; Schleyer, P. v. R. Hyperconjugative $\pi$-Aromaticity: How To Make Cyclopentadiene Aromatic. J. Am. Chem. Soc. 1999, 121, 6872-6875. (b) Schleyer, P. v. R.; Nyulászi, L.; Kárpáti, T. To What Extent Can NineMembered Monocycles Be Aromatic? Eur. J. Org. Chem. 2003, 10, 1923-1930. (c) Fernández, I.; Wu, J. I.; Schleyer, P. v. R. Substituent Effects on "Hyperconjugative" Aromaticity and Antiaromaticity in Planar Cyclopolyenes. Org. Lett. 2013, 15, 2990-2993. (d) Levandowski, B. J.; Zou, L.; Houk, K. N. Schleyer hyperconjugative aromaticity and Diels-Alder reactivity of 5-substituted cyclopentadienes. J. Comput. Chem. 2016, 37, 117-123.

(27) The electronegativities of nitrogen and oxygen are, respectively, 3.0 and 3.5 on the Pauling scale.

(28) (a) Fukuzumi, S.; Kochi, J. K. Electron transfer activation of the Diels-Alder reaction: Quantitative relationship to charge transfer excited states. Tetrahedron 1982, 38, 1035-1049. (b) Sustmann, R.; Korth, H.-G.; Nüchter, U.; Siangouri-Feulner, J.; Sicking, W. Are Charge-Transfer Complexes Intermediates in Diels-Alder Reactions? A Case Study of the Reaction of 1,2-Dimethylenecyclopentane with Tetracyanoethylene. Eur. J. Inorg. Chem. 1991, 124, 2811-2817. (c) Korchowiec, J. Role of charge-transfer effects in regioselectivity. Int. J. Quantum Chem. 2005, 101, 714-721. (d) Domingo, L. R.; Sáez, J. A. Understanding the mechanism of polar Diels-Alder 
reactions. Org. Biomol. Chem. 2009, 7, 3576-3583. (e) Rosokha, S. V.; Korotchenko, V.; Stern, C. L.; Zaitsev, V.; Ritzert, J. T. Substituent-Induced Switch of the Role of Charge-Transfer Complexes in the Diels-Alder Reactions of o-Chloranil and Styrenes. J. Org. Chem. 2012, 77, 5971-5981. (f) Sexton, T.; Kraka, E.; Cremer, D. Extraordinary Mechanism of the Diels-Alder Reaction: Investigation of Stereochemistry, Charge Transfer, Charge Polarization, and Biradicaloid Formation. J. Phys. Chem. A 2016, 120, 1097-1111. (g) Shimizu, R.; Okada, Y.; Chiba, K. Stepwise radical cation Diels-Alder reaction via multiple pathways. Beilstein J. Org. Chem. 2018, 14, 704-708. (h) Levandowski, B. J.; Hamlin, T. A.; Helgeson, R. C.; Bickelhaupt, F. M.; Houk, K. N. Origins of the Endo and Exo Selectivities in Cyclopropenone, Iminocyclopropene, and Triafulvene Diels-Alder Cycloadditions. J. Org. Chem. 2018, 83, 3164-3170.

(29) (a) Westerhausen, M.; Stein, B.; Ossberger, M. W.; Görls, H.; Ruiz, J. C. G.; Nöth, H.; Mayer, P. Diels-Alder cycloaddition reaction of 1,1-dichloro-2,3,4,5-tetraethylgermole and 1-chloro-2,3,4,5-tetraethylphosphole with maleic acid anhydride and maleimide. ARKIVOC 2007, Part (iii), 46-59. (b) Laporterie, A.; Manuel, G.; Dubac, J.; Mazerolles, P.; Iloughmane, H. J. Organomet. Chem. 1981, 210, C33-C36.

(30) Alder, K.; Stein, G. Untersuchungen über den Verlauf der Diensynthese. Angew. Chem. 1937, 50, 510-519.

(31) (a) Hoffmann, R.; Woodward, R. B. Orbital Symmetries and endo-exo-Relationships in Concerted Cycloaddition Reaction. J. Am. Chem. Soc. 1965, 87, 4388-4389. (b) Hoffmann, R.; Woodward, R. B. Orbital Symmetries and Orientational Effects in a Sigmatropic Reaction. J. Am. Chem. Soc. 1965, 87, 4389-4390.

(32) (a) Wassermann, A. The Mechanism of addition to double bonds. Part II. The steric course of two diene syntheses. J. Chem. Soc. 1935, 1511-1514; (b) Williamson, K. L.; Hsu, Y. F. L. Stereochemistry of the Diels-Alder reaction. II. Lewis acid catalysis of syn-anti isomerism. J. Am. Chem. Soc. 1970, 92, 7385-7389. (c) Furukawa, J.; Kobuke, Y.; Fueno, T. Endo selectivities of some methyl-substituted dienophiles in Diels-Alder reactions with cyclopentadiene. $J$. Am. Chem. Soc. 1970, 92, 6548-6553. (d) Kobuke, Y.; Sugimoto, T.; Furukawa, J.; Fueno, T. Role of attractive interactions in endo-exo stereoselectivities of Diels-Alder reactions. J. Am. Chem. Soc. 1972, 94, 3633-3635.

(33) (a) Sustmann, R.; Boehm, M.; Sauer, J. Effect of diene 1,4-distance on the reactivity in Diels-Alder reactions Chem. Ber. 1979, 112, 883-889. (b) Scharf, H. D.; Plum, H.; Fleischhauer, J.; Schleker, W. Diels-Alder reactivity of $s$-cis-fixed 1,3-dienes. Chem. Ber. 1979, 112, 862-882. (c) Vogel, P; Houk, K. N. in Organic Chemistry: Theory, Reactivity and Mechanisms in Modern Syntheses, Wiley-VCH, 2019, Chapter 5.3.12.

(34) (a) Wiberg; K. B.; Nakaji, D. Y.; Morgan, K. M. Heat of hydrogenation of a cis imine. An experimental and theoretical study. J. Am. Chem. Soc. 1993, 115, 3527-3532. (b) Wiberg, K. B.; Nakaji, D.; Breneman, C. M. Azines. A theoretical study of .pi-electron delocalization. J. Am. Chem. Soc. 1989, 111, 4178-4190.

(35) Boger, D. L. Diels-Alder Reactions of Heterocyclic Azadienes: Scope and Applications. Chem. Rev. 1986, 86, 781-793. 
(36) For theoretical calculations of the DA reactions of benzene and naphthalene, see: Kiselev, V. D.; Kashaeva, E. A.; Potapova, L. N.; Iskhakova, G. G. Diels-Alder reaction between naphthalene and $N$-phenylmaleimide under mild conditions. Russ. Chem. Bull. 2004, 53, 51-54. For DA reaction of naphthalene at elevated temperature and pressure, see: (a) Jones, W. H.; Mangold, D.; Plieninger, H. Diensynthesen under hohem druck. Tetrahedron 1962, 18, 267-272. (b) Klarner, F.-G.; Breitkopf, V. The Effect of Pressure on Retro Diels-Alder Reactions. Eur. J. Org. Chem. 1999, 2757-2762. For DA reaction of naphthalene under co-encapsulated condition, see: Murase, T.; Horiuchi, S.; Fujita, M. Naphthalene Diels-Alder in a Self-Assembled Molecular Flask. J. Am. Chem. Soc. 2010, 132, 2866-2867.

(37) For temperature effect on the Diels-Alder reaction of furan with maleic anhydride and maleimide, see: Yadav, V. K.; Prasad, D. L. V. K.; Yadav, A.; Yadav, K. On the solvent and temperature driven stereoselectivity of the DielsAlder cycloaddition reactions of furan with maleic anhydride and maleimide. ChemRxiv. Preprint. (2019) https://doi.org.10.26434/chemrxiv.11410059.v1

(38) Papaspyrou, A.; Spyropoulou, K.; Paraskevas, M. S.; Paraskevas, S. M. Synthesis and Electron Spin Resonance Studies of $\mathrm{Cu}(\mathrm{II})$ Complexes with Schiff Base Macroligands. Synthesis and Reactivity in Inorganic, Metal-Organic, and Nano-Metal Chemistry 2008, 38, 623-628. However, for a report on the formation of a single product, see: Leont'eva, S. V.; Manulik, O. S.; Evstigneeva, E. M.; Bobkova, E. N.; Flid, V. R. Unconventional catalytic allylation of 5-norbornene-2,3-dicarboxylic anhydrides: 7-oxa and 7-aza analogues. Kinet.Catal. 2006, 47, 384-388.

(39) Woodward, R. B.; Baer, H. The Reaction of Furan with Maleic Anhydride. J. Am. Chem. Soc. 1948, 70, 11611166. 


\section{Table of Contents}

A computational study of the relative aromaticity of pyrrole, furan, thiophene and selenophene, and their stereoselectivities in Diels-Alder reactions

Veejendra K. Yadav*

The interaction energy of heteroatom lone pair with ring $\pi$ bonds suggests the relative aromaticity order to be pyrrole $>>$ furan $>$ thiophene $>$ selenophene. The activation energies of Diels-Alder reactions of thiophene and selenophene depend more on termini separation of the diene than their resonance energies unlike pyrrole and furan.

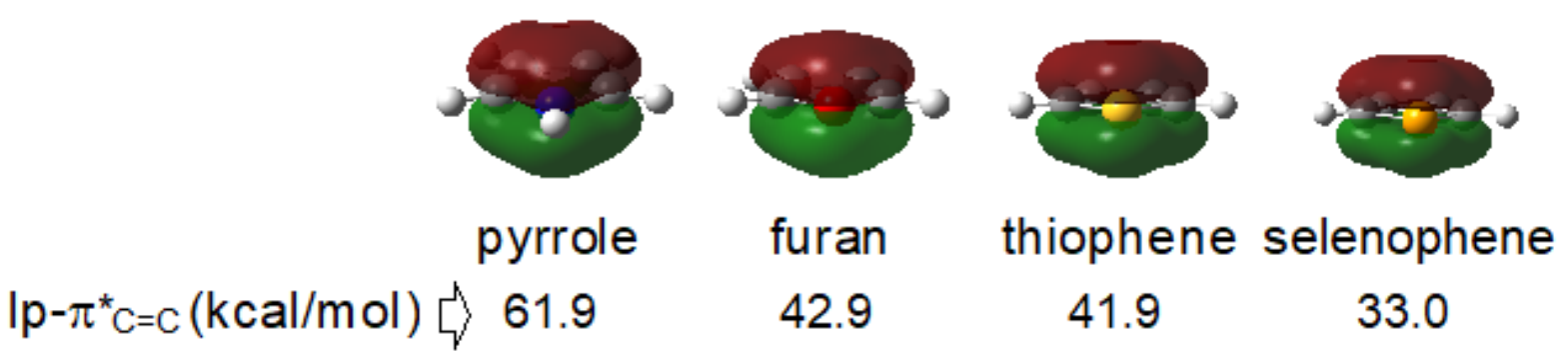

